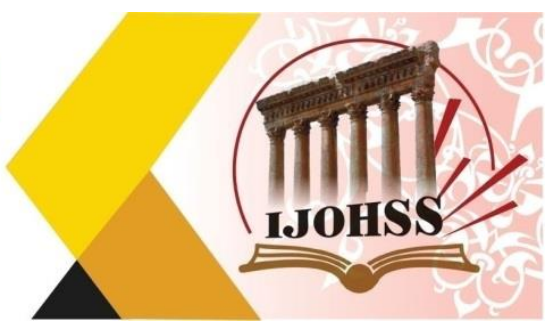

\title{
تعزيز الانتماء في الفضاء الداخلي (المقاهي البغدادية)
}

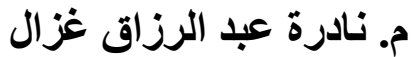

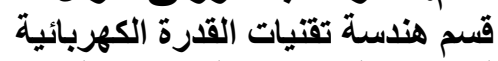 \\ الكلية التقنية الهندسية الكهربائية ـ الجامعة التقنية التوبية الوسطى

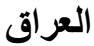 \\ البريد الاكتروني: nadirahabd6@gmail.com
}

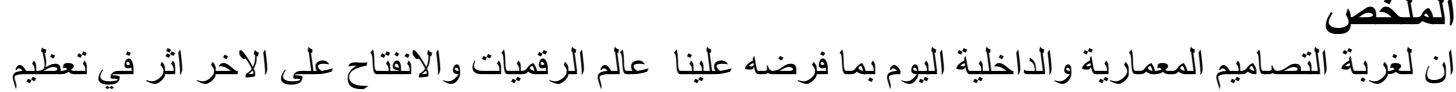

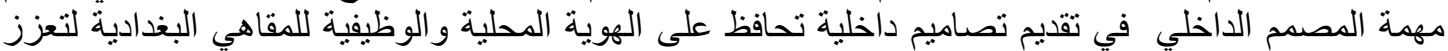

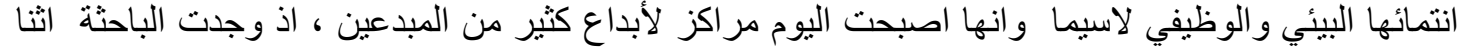

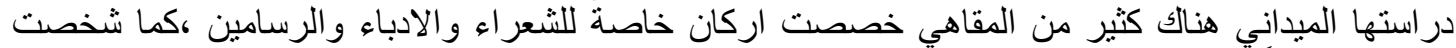

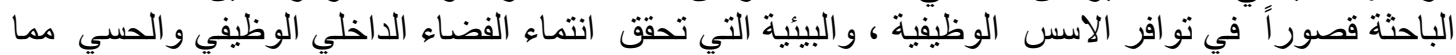

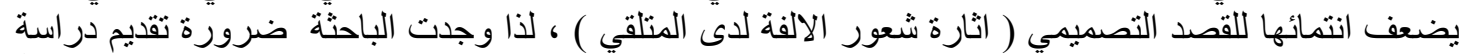

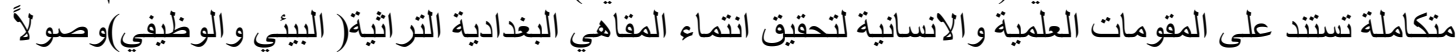

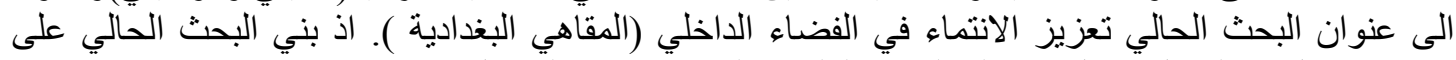

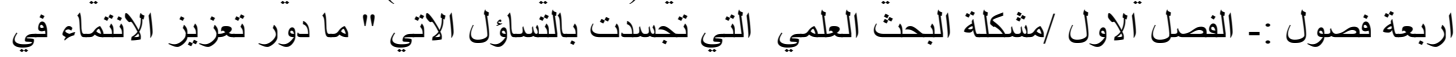

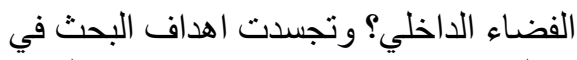

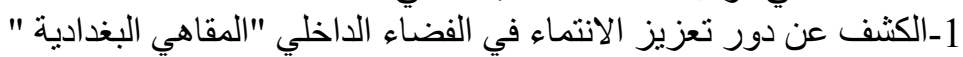

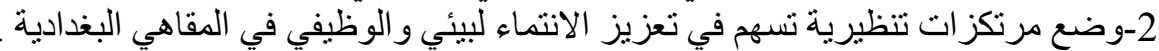

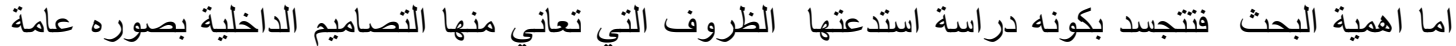

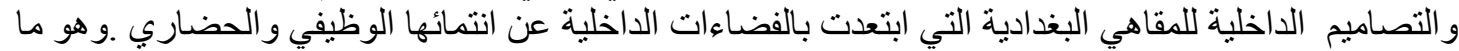

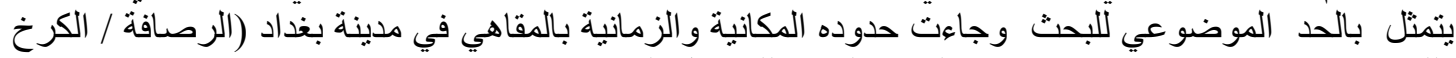

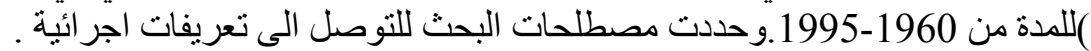

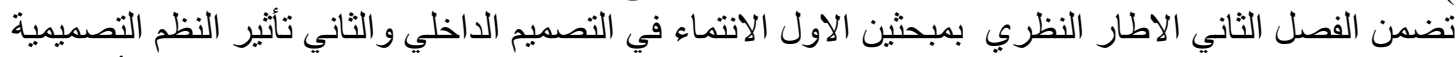

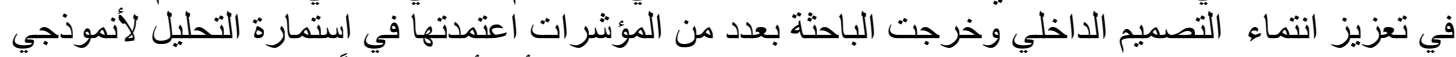

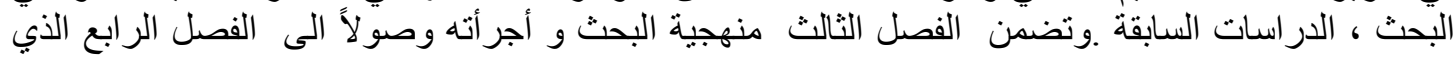

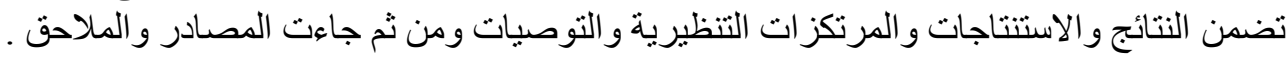




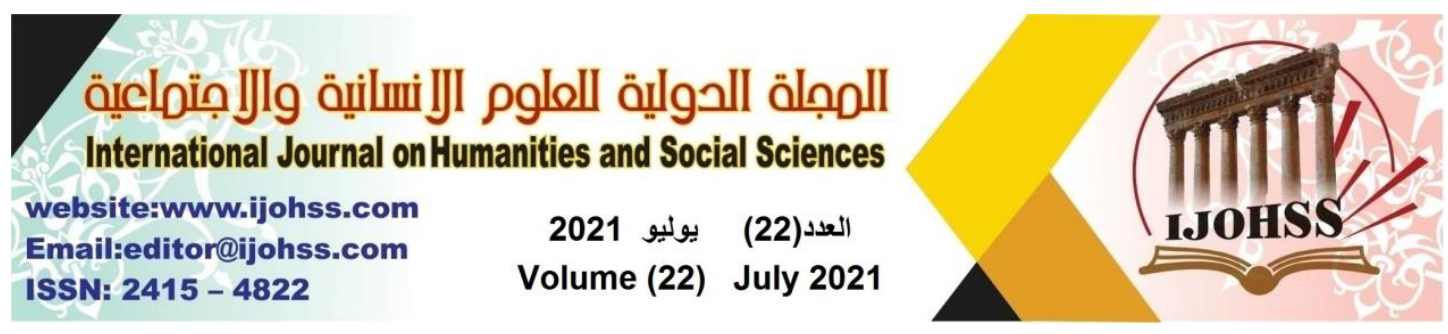

\title{
Strengthening the Belonging to the Interior Building (Iraqi Coffee shops)
}

\author{
Lect. Nadera Abdul Razzaq Ghazal \\ Electrical Engineering Technical College - Central Technical University \\ Iraq \\ Email: nadirabd6@gmail.com
}

\begin{abstract}
The strangeness of the interior and architectural designs nowadays including to what the digital and democratic world obliged upon us has an impact on the mission of enlarging the interior design as well as in presenting interior designs help in maintaining the local and functional identity of the Iraqi coffee shops in order to strengthen their environmental and functional belonging. Iraqi coffee shops become the center of creativity for many creators. The researcher finds in her filed study there are many coffee shops have specialized special corners for poets, writers and painters. Besides, the researcher has noticed inadequate availability of functional and environmental foundations which fulfill the interior, functional and emotional belonging and in the same time weaken their belonging to the intended design (tackling the recipient's feeling of familiarity). The researcher finds the necessity of presenting a well-complete study depends on scientific and humanity bases to reach to the stage of belonging of the Iraqi heritage coffee shops (environmental \& functional) reaching to the title of the current study which is "Strengthening the belonging to the interior building (Iraqi Coffee shops). The current upon consists of four chapters:

The first chapter/ Statement of the research problem embodied in the following question: what is the role of strengthening the belonging in the interior building? and the objectives of the study are represented in the following points:

1. Discovering the role of strengthening the belonging in the interior building (Iraqi Coffee shops).

2. Putting theoretical backgrounds contribute in strengthening the environmental and functional belonging of the Iraqi coffee shops.

However, the significance of the study is represented by the idea that the current study is a study appears due to the conditions the interior designs suffer from in general and the interior design of Iraqi coffee shops in particular which lose in their interior designs their functional and cultural belonging that also symbolize the limitation of the study. Therefore, the spatial and temporal limitations of the current study represented by the coffee shops in Baghdad city (Rusafa/ Karkh) for the period 1960-1995. Additionally, the researcher has identified the keywords of the study in order to obtain the procedural definitions.
\end{abstract}

Keywords: Strengthening belonging, interior design and intended designing. 


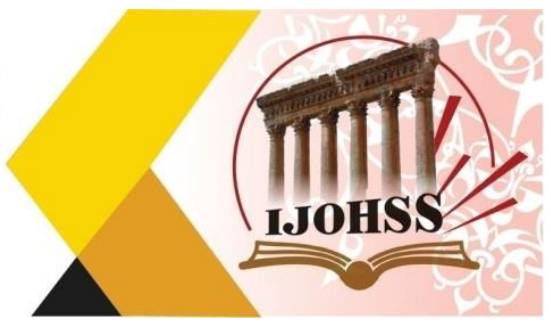

الفصل الاول

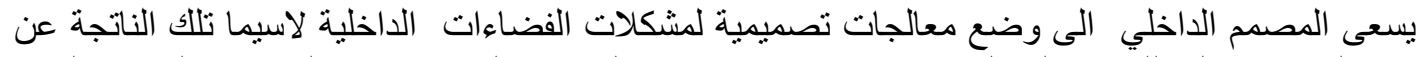

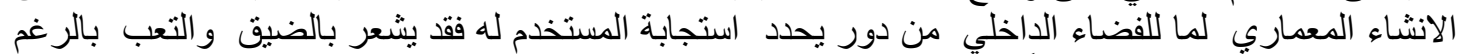

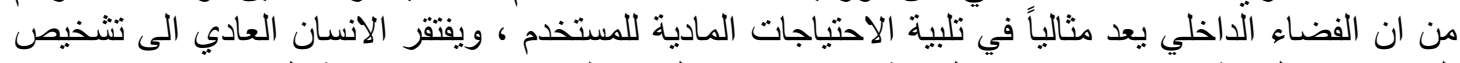

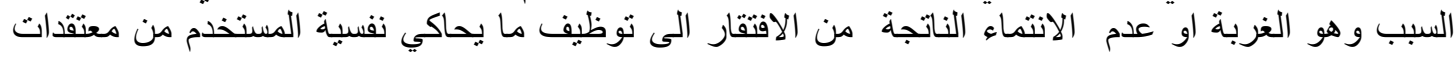

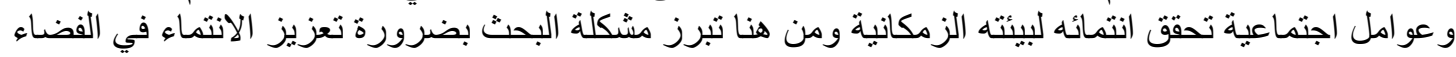

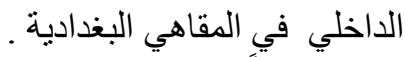

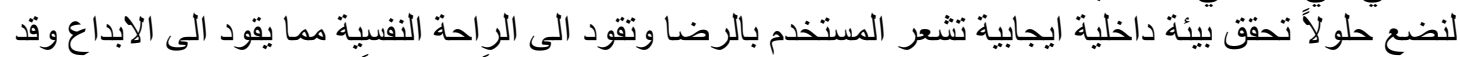

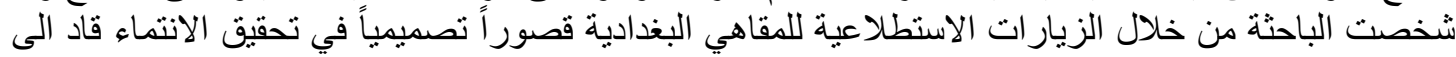

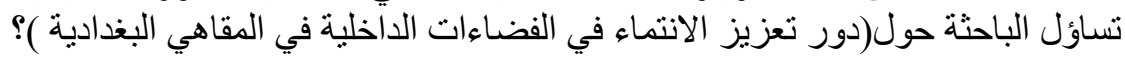

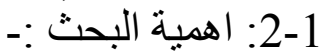

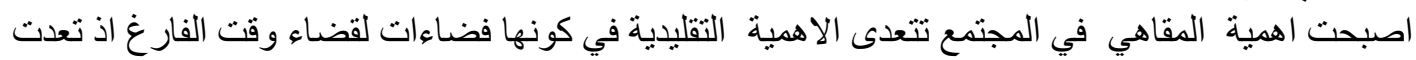

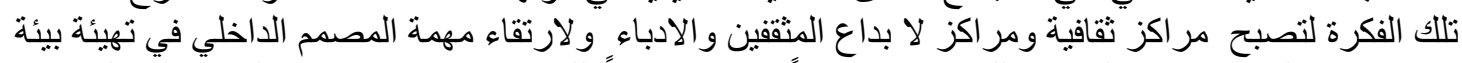

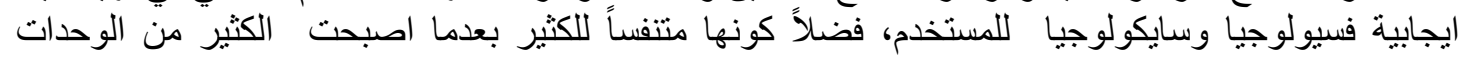

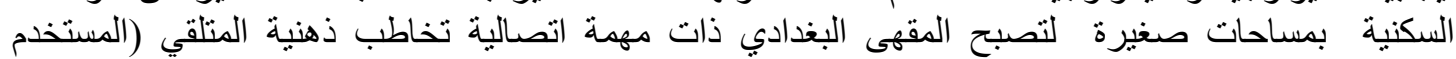

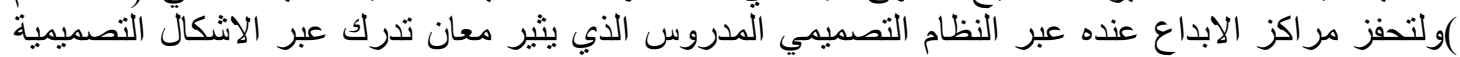

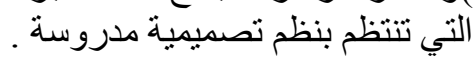
تتجلَى اهمية البحث في تحقيق اضافة معرفية للعلوم المعمارية و التصميمية الداخلية و الباحثين بها . 3-1

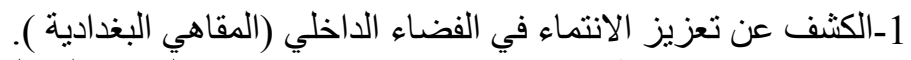

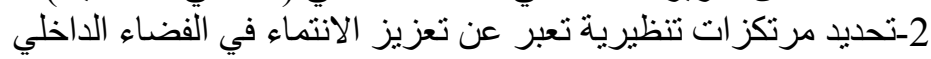
4-1

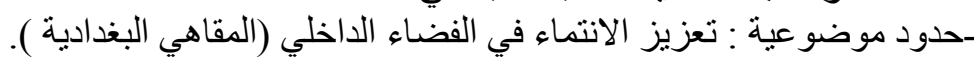

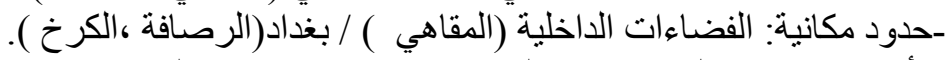

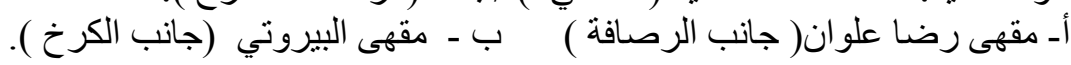
- حدود زمانية :-1960- 1995

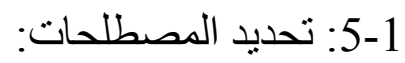
الانتماء

تعزيز :- لغة تعزيز بالفتح من عزز وهو العز ضد الذوب الذل والتعزيز فهو التوقير والتعظيم وبالفتح فهو عزيز أي

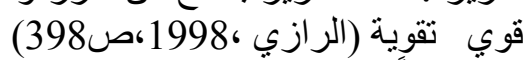

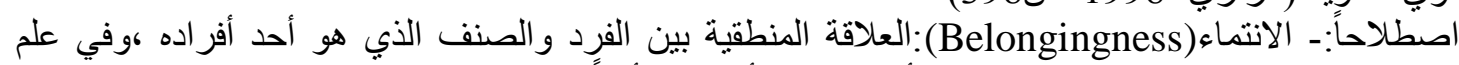

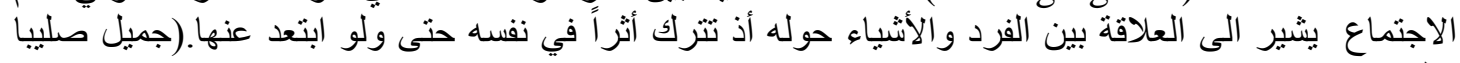

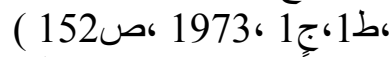
اجر ائيا: توظيف عناصر التُاء التصميم الداخلي بنظم تصميمية مدروسة لتحقق تعزيز انتماء التصميم الداخلي بالتالي

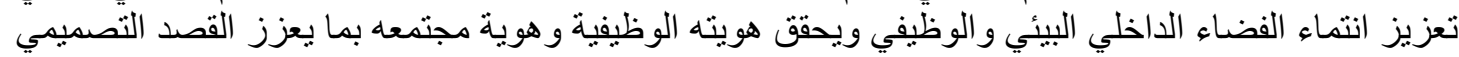

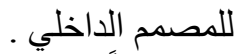
اصطلاحاً: الفضياءات الداخلية:هي تلك الفضاءات التي تم تكوينها من بنية ظاهرية و عميقة ذات مو اصفات تعبر

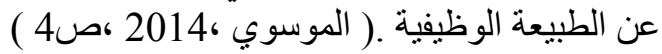

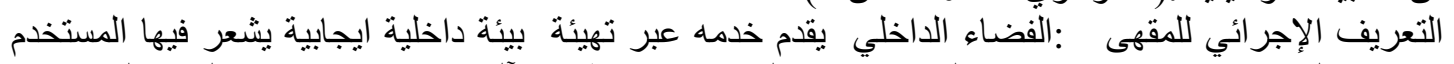

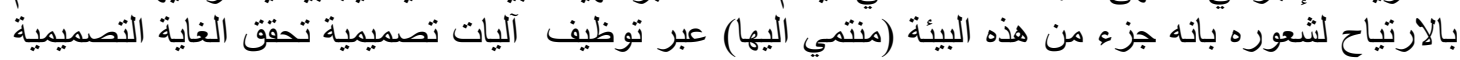
بما ينسجم والذوق العام وتو بانه جزء من زمكا نيته 


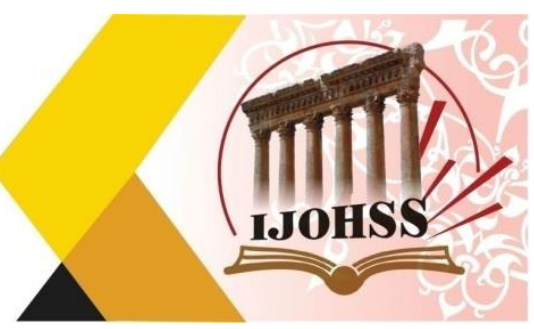

الاطار النظري والاراسات السابقة المبحث الاول :2-1 مفهوم الانتماء:-

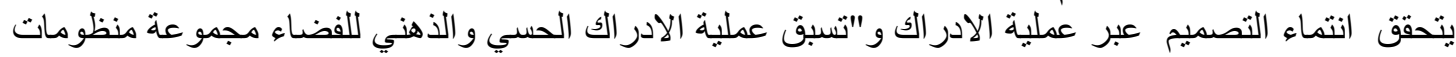

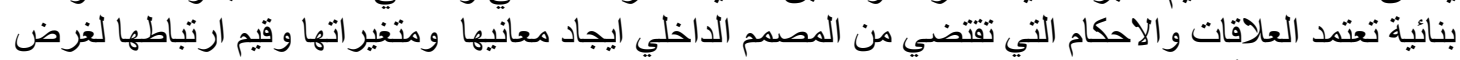

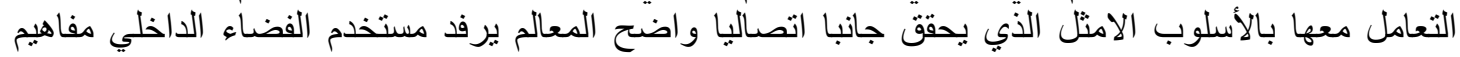

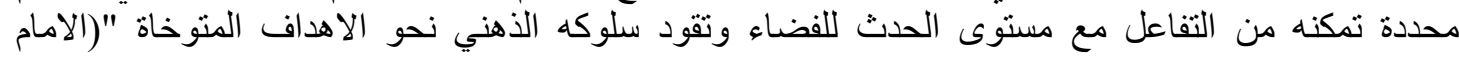
(34)2013، ان لكل تصميم غاية او قصد تصميمي بسعى مصممه الداخلي الى تحقيقه عبر الياته التصميمية المادية

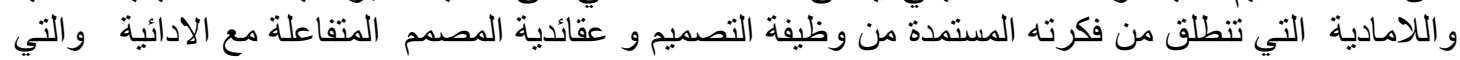

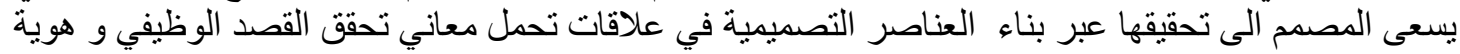

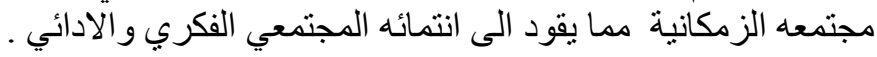

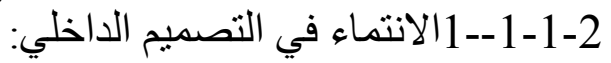

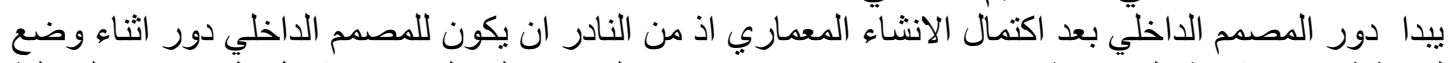

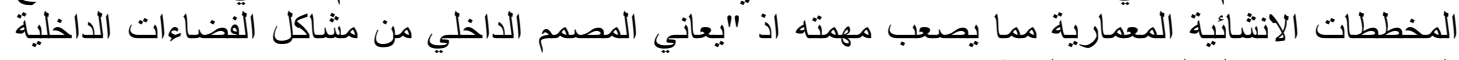

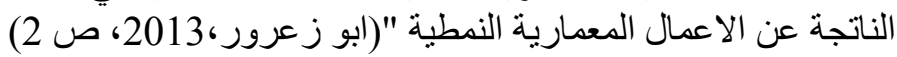

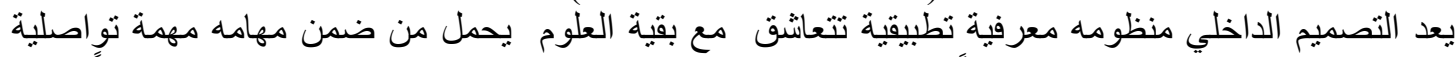

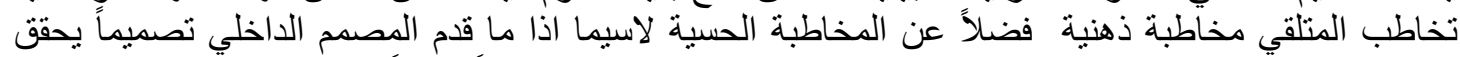

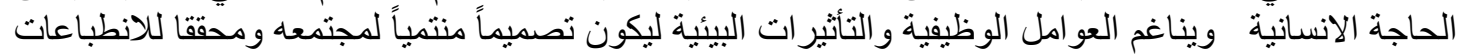

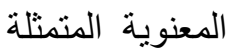
ب:-غاية الفكرة التصميمية الابداعية اذ يسعى الصصمم الداخلي الى تقديم بيئة داخلية تلبي احتياجات

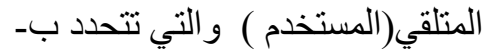
1 - 1-نمط شاغلي الفضاء 2 - طبيعة الوظيفة التي ستمارس في الفضاء. 3-فلسفة المصمم فضتلا عن فلسفة المجتمع (فما يصلح في المجتمع الاوربي لا يصلح في بعض فقراته في

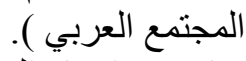
بما يحقق انتماء الفضاء الوظيفي و الثقافي عبر توظيف الثكل بعلاقات تصميمية تحقق هوية الفضاء الديناميكية

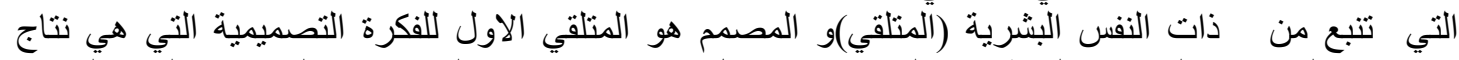

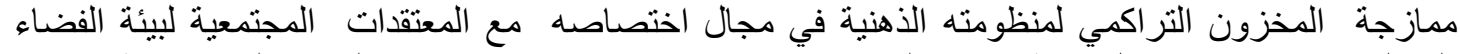

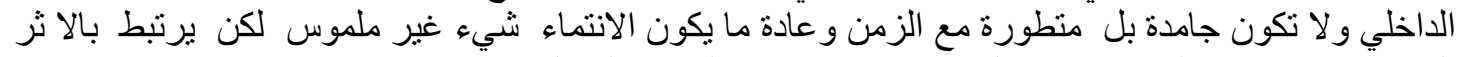

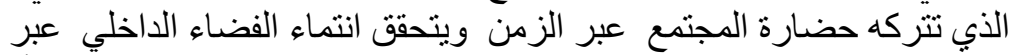

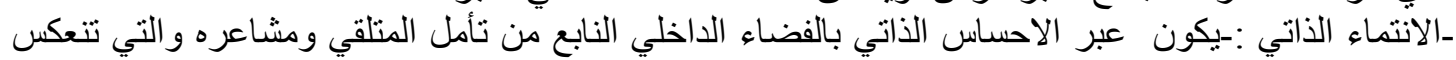

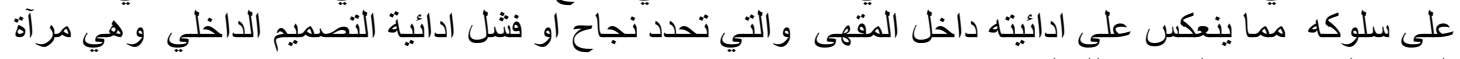

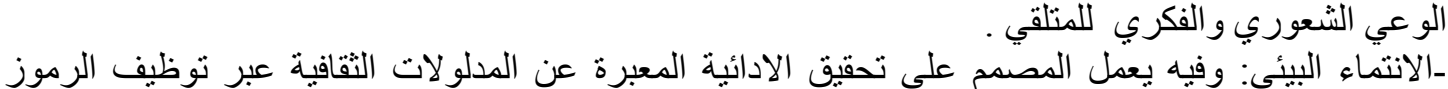

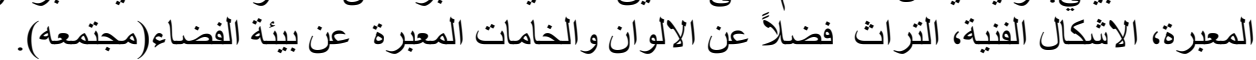

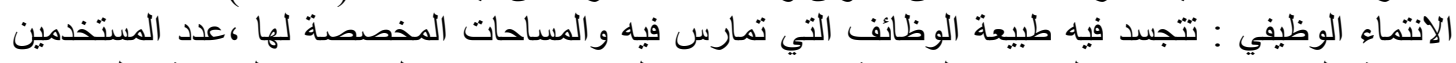

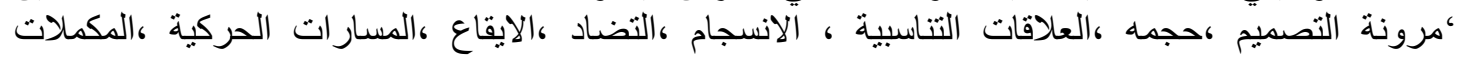

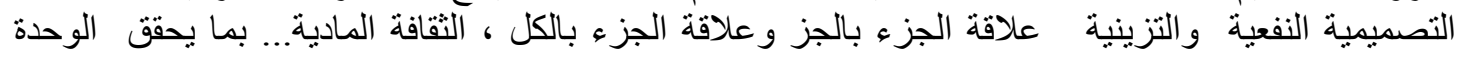
التصميمية وبالتالي يحقق الاداء الوظيفي الذية يقود الى نظام تصميمي مريح دون تثنويش للمتلقي (المستخدم).

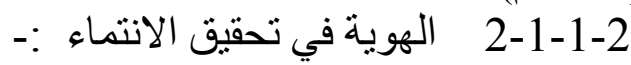
"ان الانتماء الذي لا بحقق الانتماء الى مجتمعه لا يمتلك شخصية متميزة وهوية فردية تؤهله ليكون شاخصاً

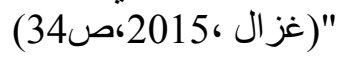




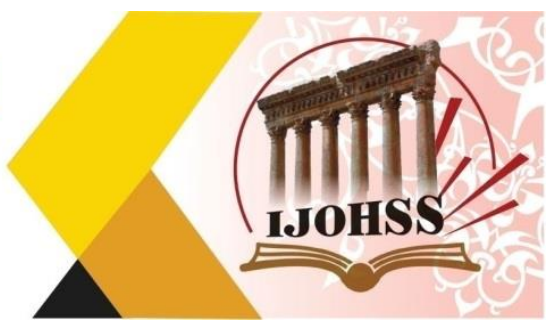

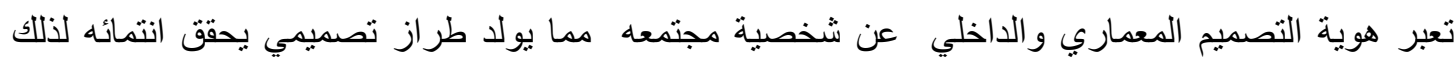

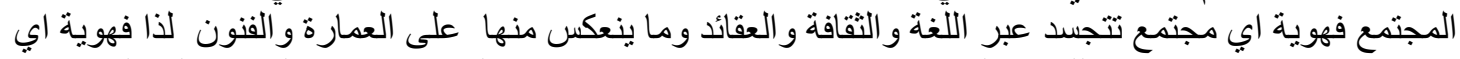

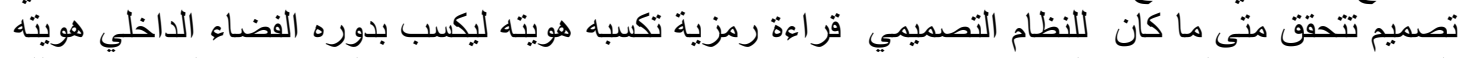

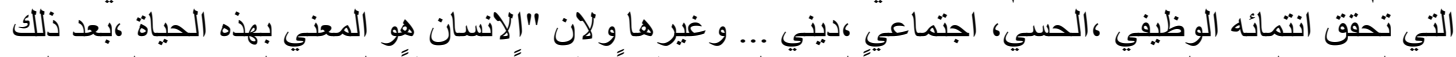

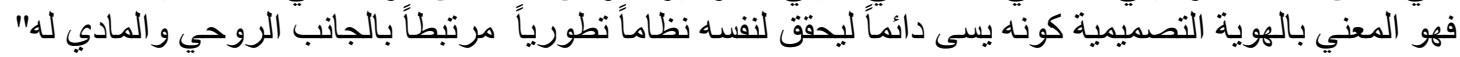

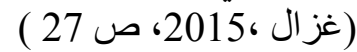
يسعى المصمم الداخلي الى تحقيق الانتماء الحسي والذهني من اجل تحقيق الثنعور بالانتماء للبيئة الداخلية

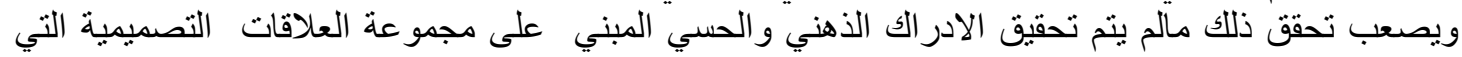

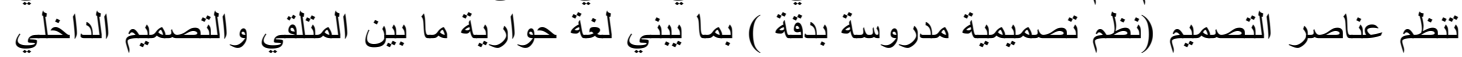

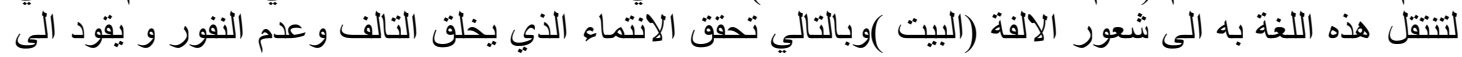

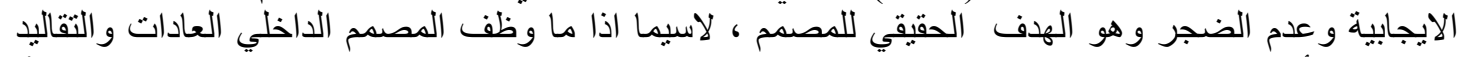

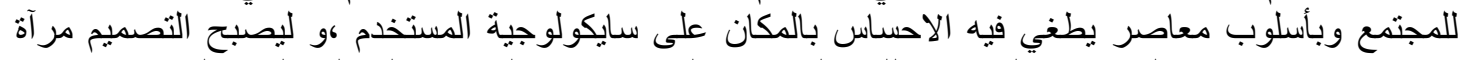

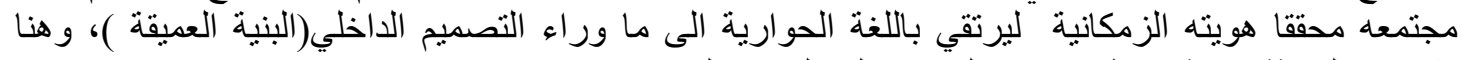

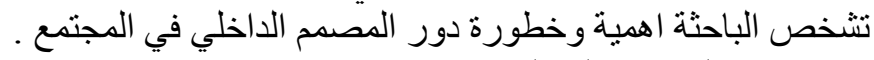

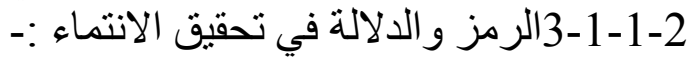

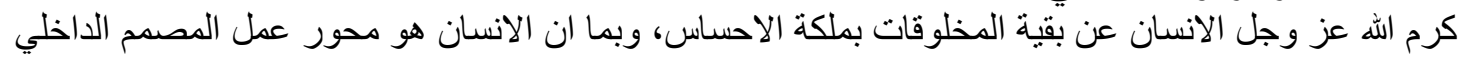

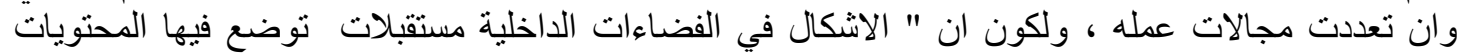

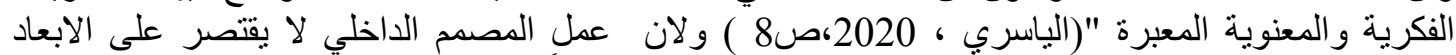

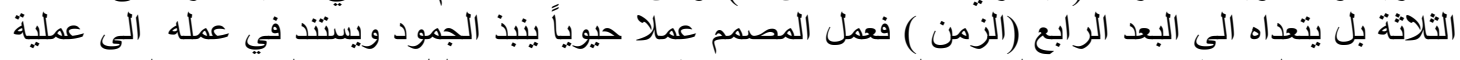

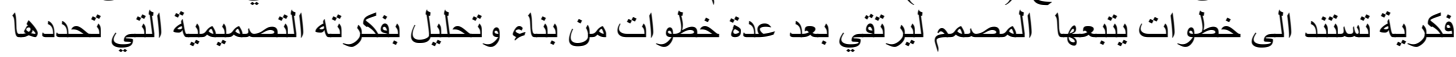

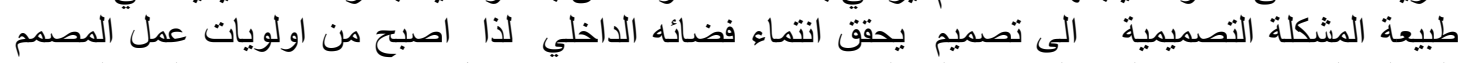

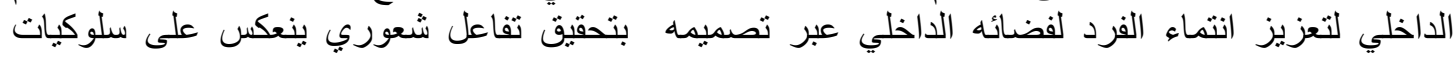

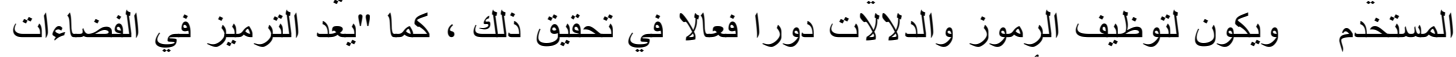

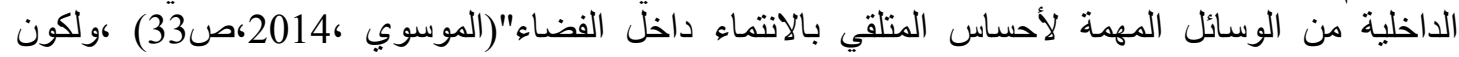

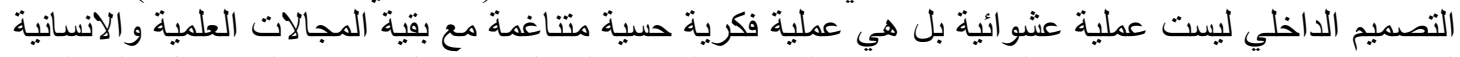

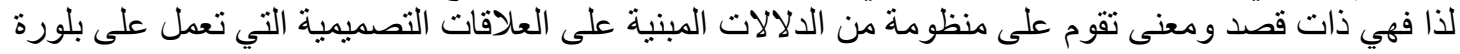

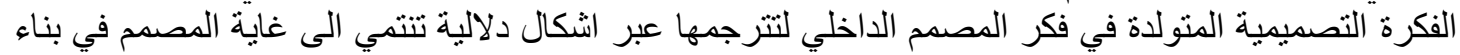

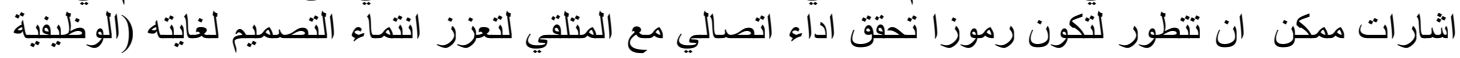

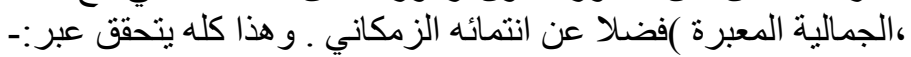

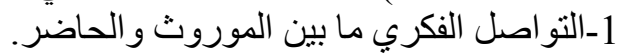

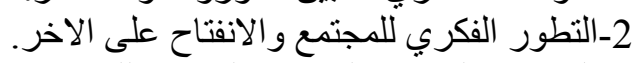

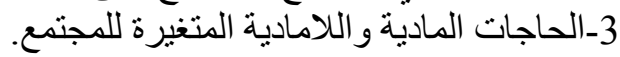

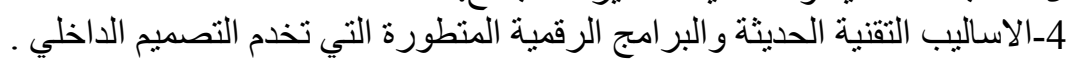

الفصل الثاني

ان 1-2-1-2 تأثير النظم التصميمية في تعزيز انتماء التصميم الداخلي:

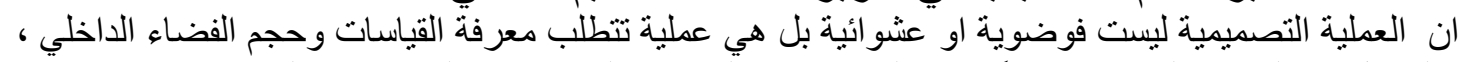

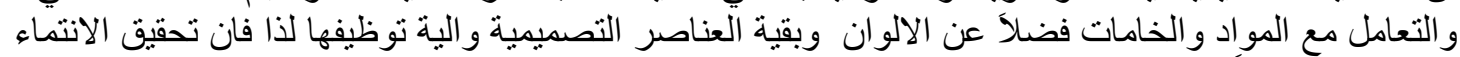

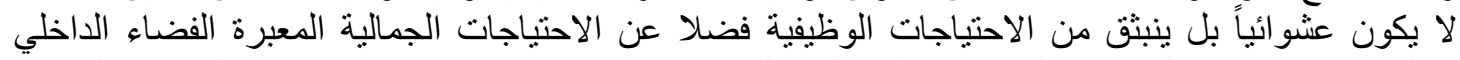

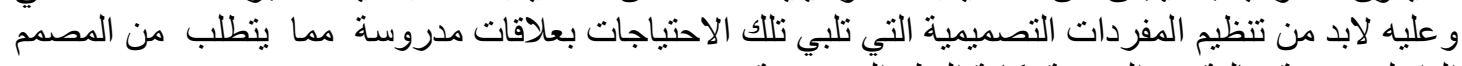

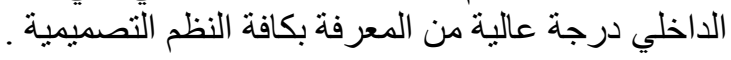




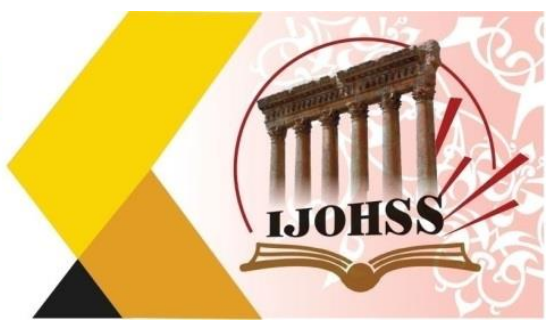

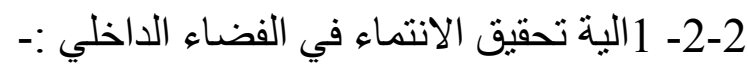

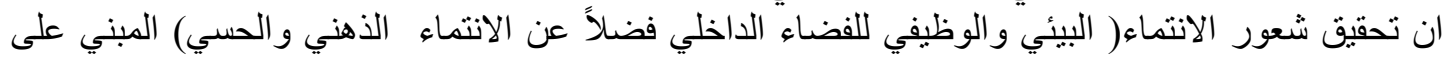

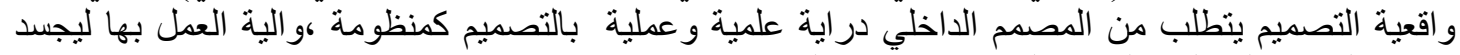

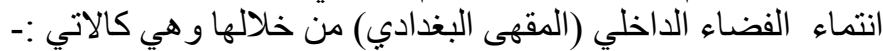

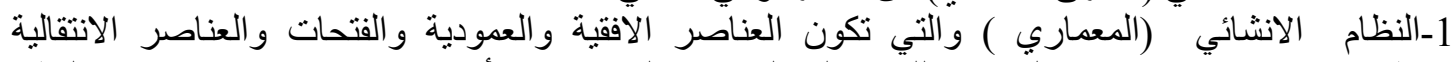

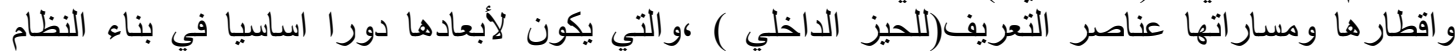

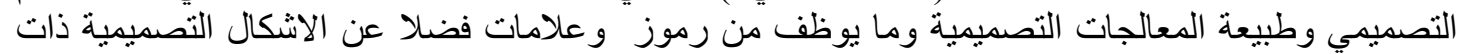

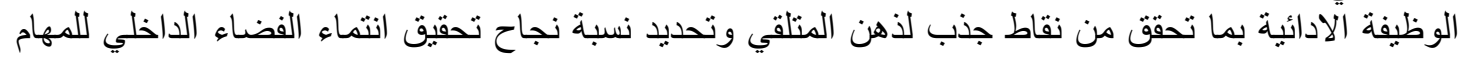

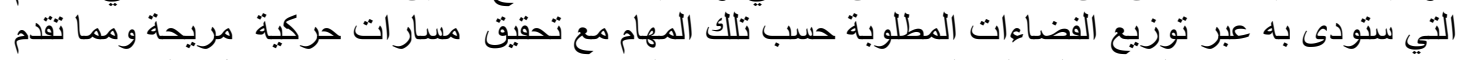

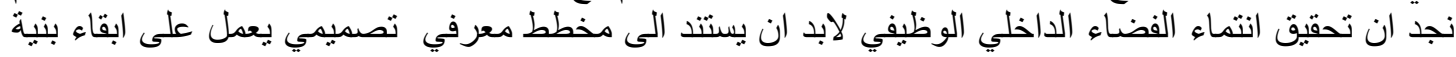

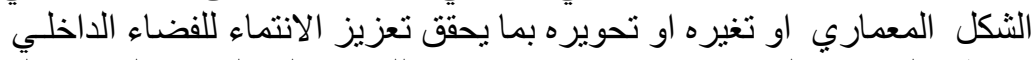

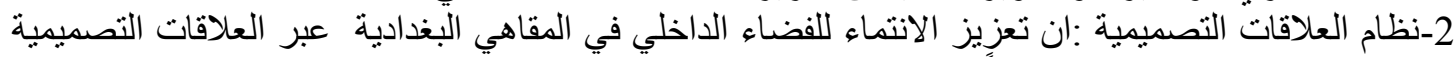

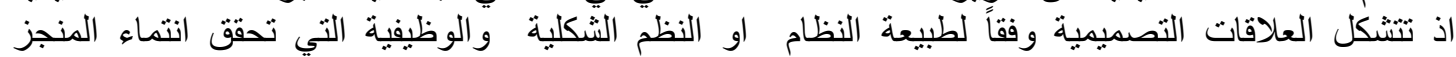

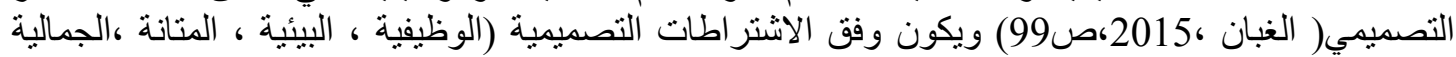

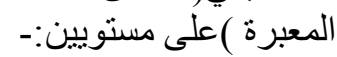

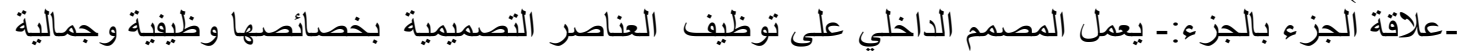

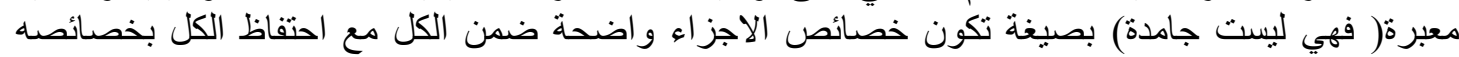

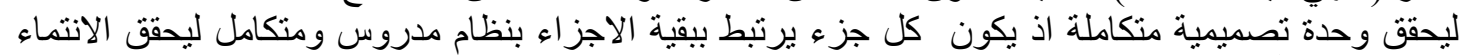

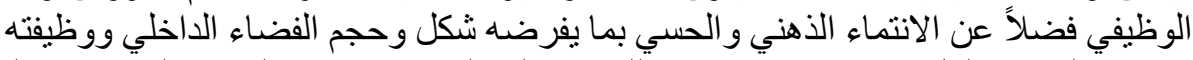

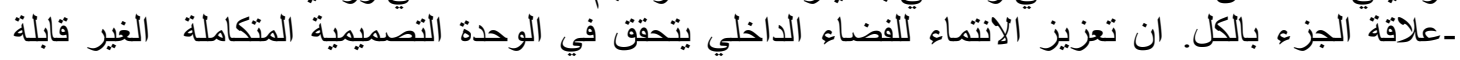

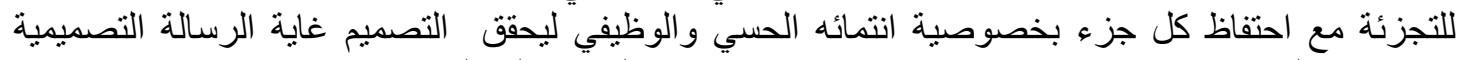

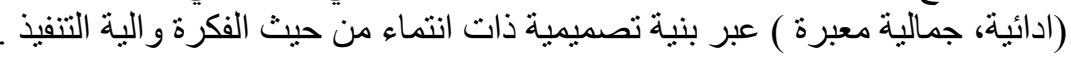

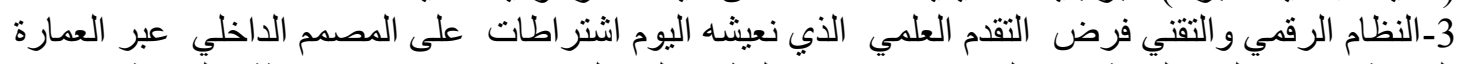

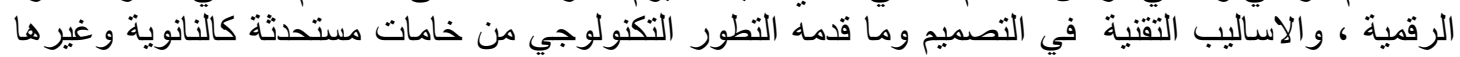

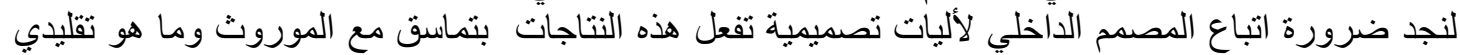

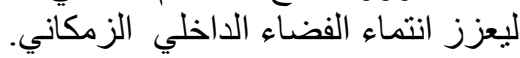

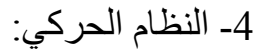

ترتبط منظومة حركة الانسان ( الفيزياوية ، البصرية ) في البيئة الداخلية بالعناصر الخاصة بتلكية البيائة الداخلية

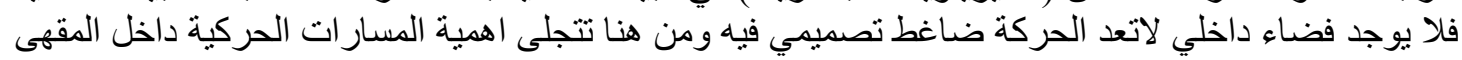

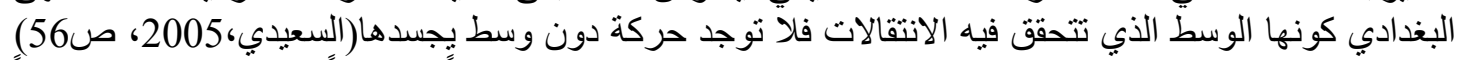

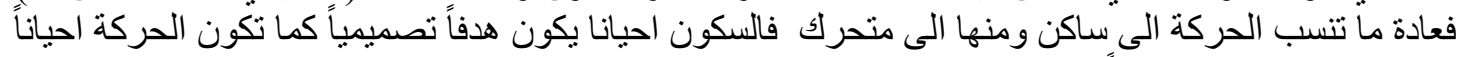

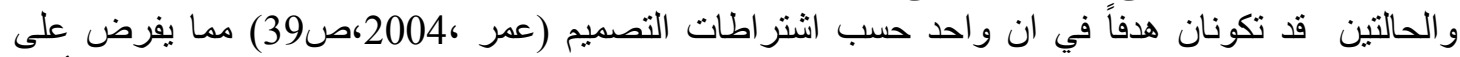

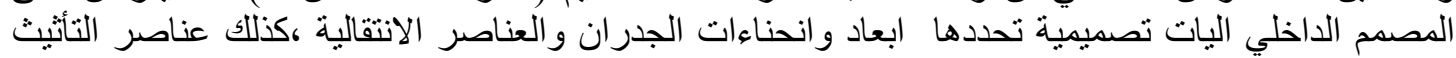

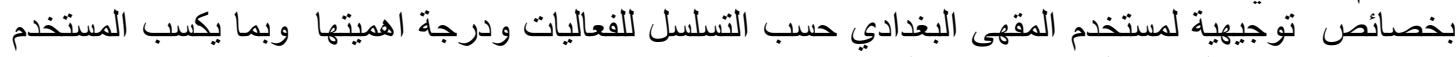

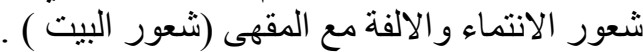

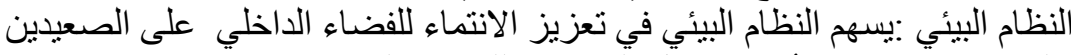

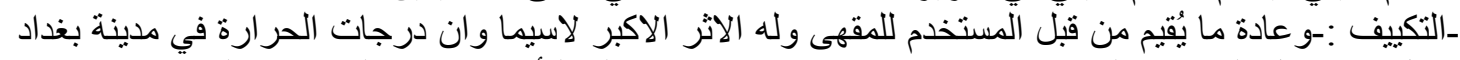

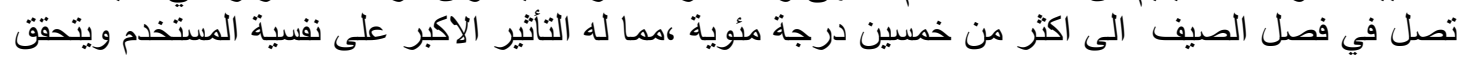
التكييف عبر خطين من المعالجة الهيف

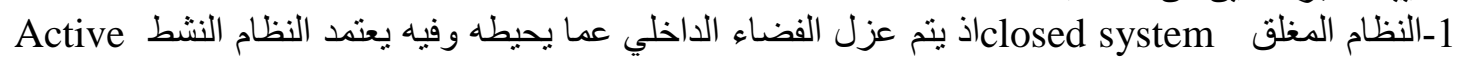
system كتوظيف اجهزة التبريد و التدفئة ميكانيكية التحكم 


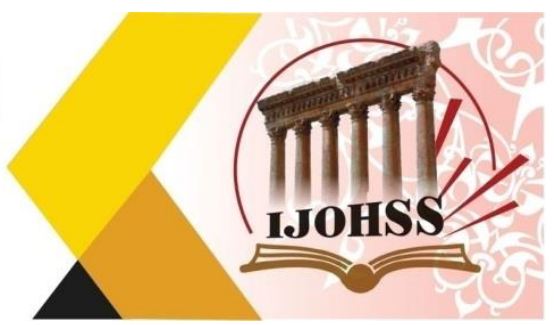

2-النظام المفتوح Open system وفيه يكون الفضاء الداخلي مفتوحاً على الفضاء الخارجي ليكمل احدهما

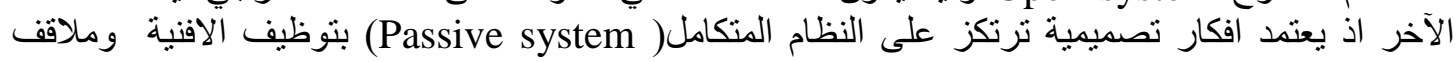

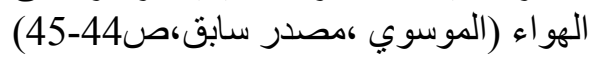

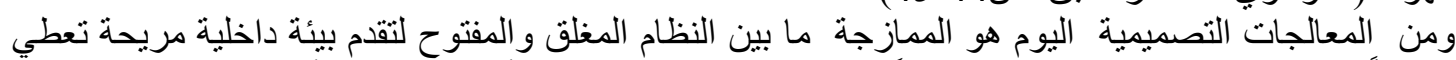

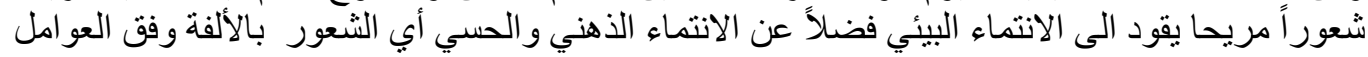

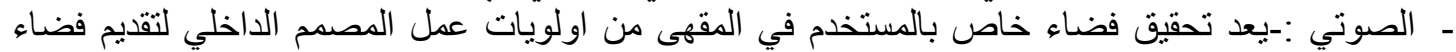

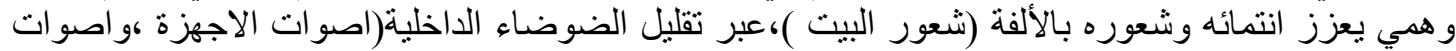

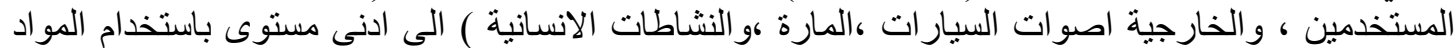

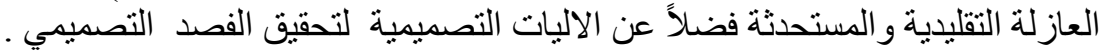

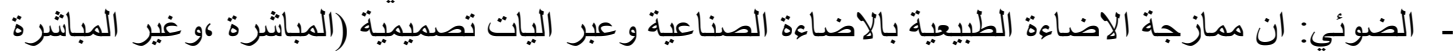

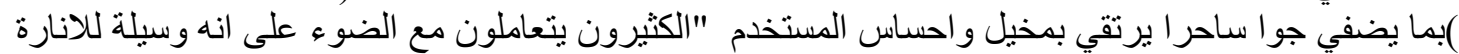

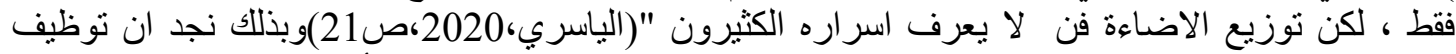

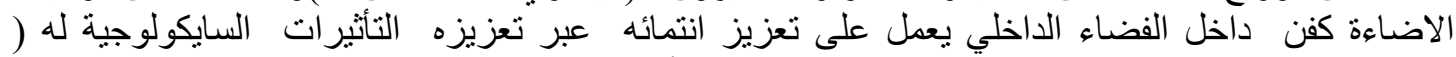

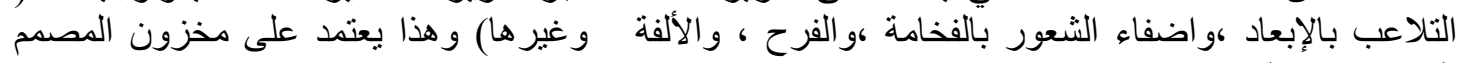

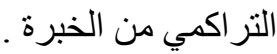

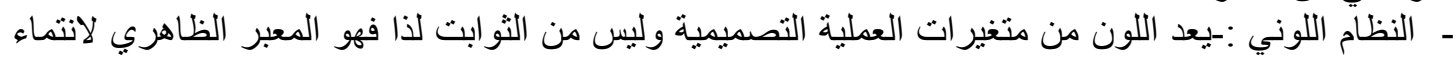

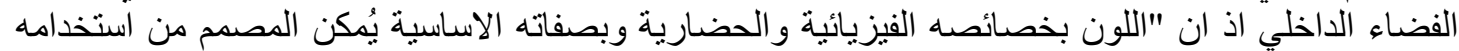

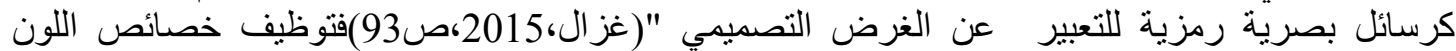

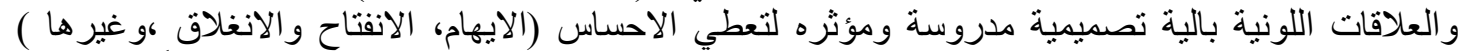

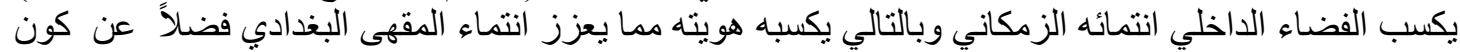

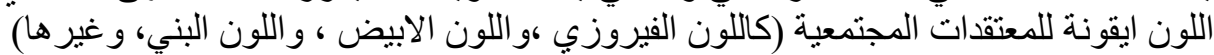

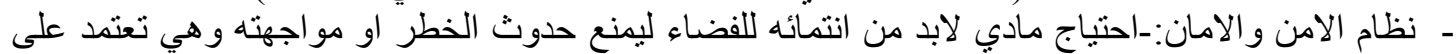

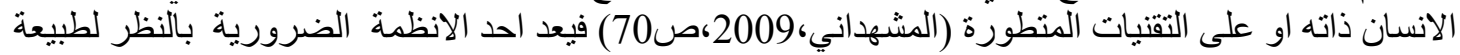

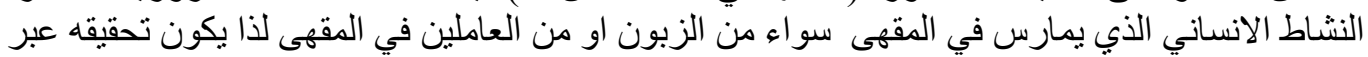

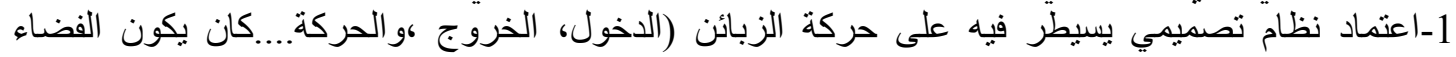

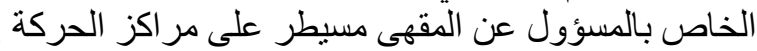

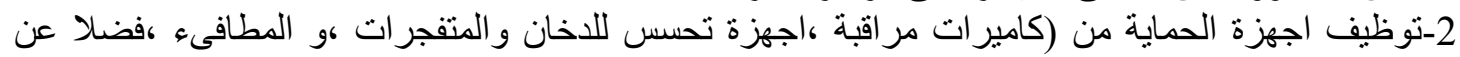
اجهزة قياس درجات الحرارة للحد من انتقال الفيروسات ، اجهزة التعقيم لاسيما ونحن نعيش عصر جائحة كورونا (ان) مما تقدم فأن توفير بيئة داخلية مريحة و امنه عبر نظام تصميمي ينسم بالتكامل يصل بنا الى تصميم ملائم ومرن

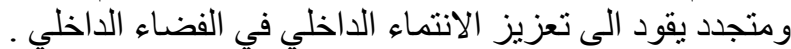

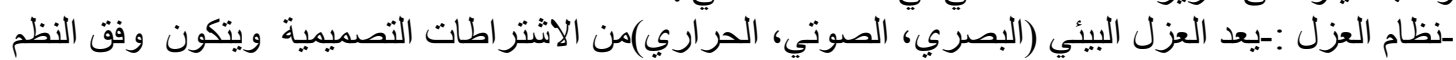
التصميمية التزول توظيف العوازل لاسيما ما يقدمه اليوم لنا النتاج التكنولوجي من نتاجات بما ينسجم وطبيعة انتماء المقهى البغدادي البيئي و الوظيفي

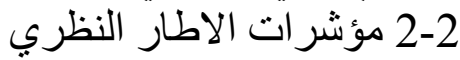

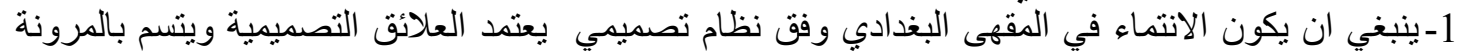

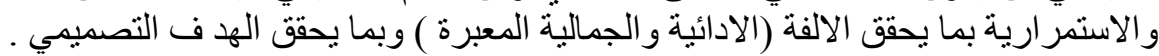

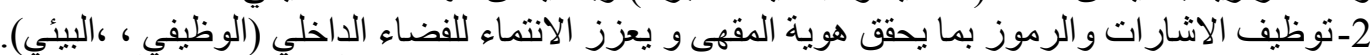

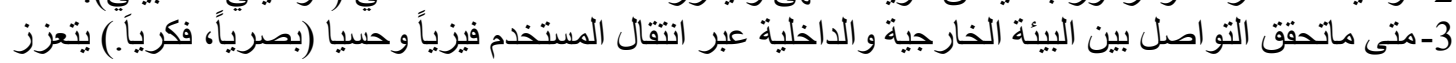
الانتماء 4- تثكل المكملات (النفعية- التزينية) انعكاسات تعبيرية لمضمون الانتماء الذهني والحسي لترصين الهدف التصميمي (الادائي - و الجمالي المعبر ) ) 


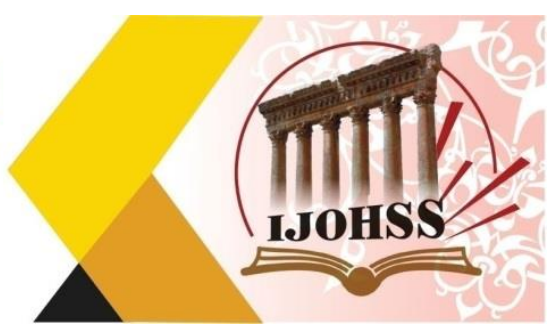

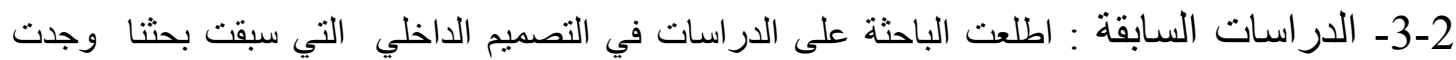

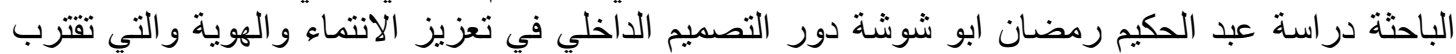

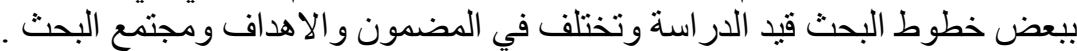

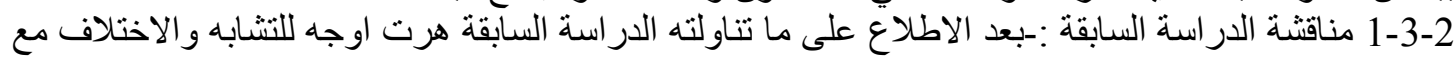

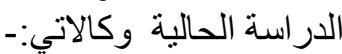

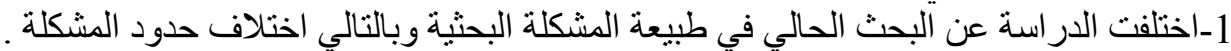

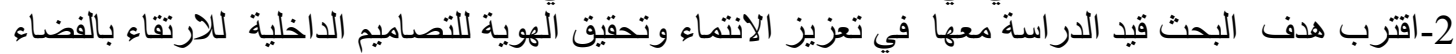

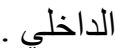
الفصل الثالث : منهجية البحث واجر اءآنه:

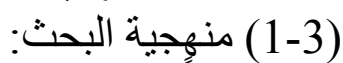

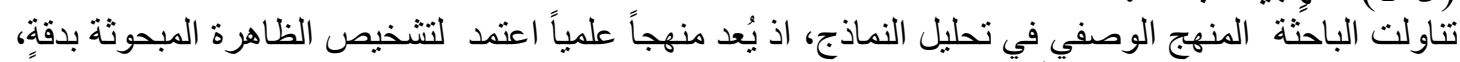

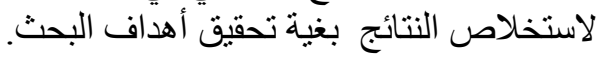

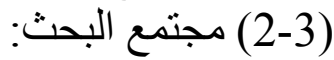

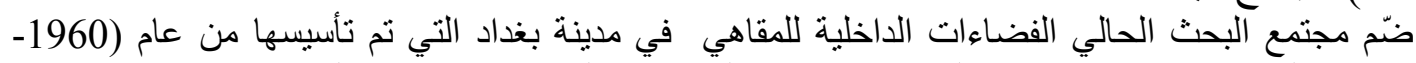

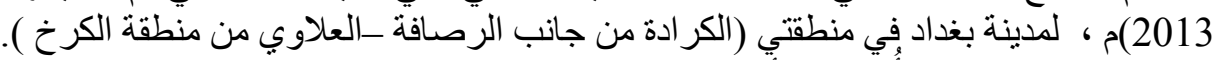

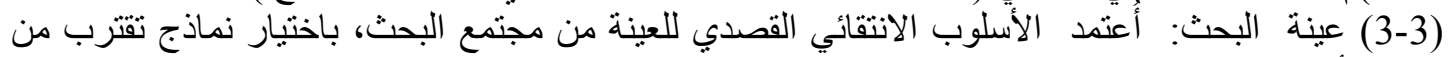

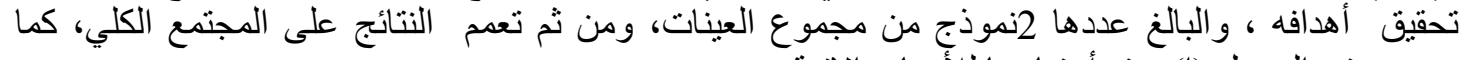

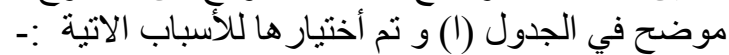

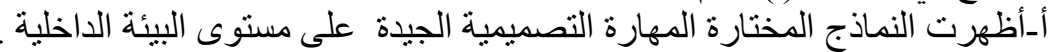

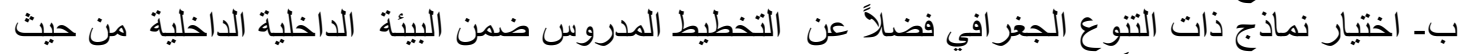
در اسة المظهر العام فضلاً عن الايقاع ألتصميمي باختيار تقنيات متنو عة ومدروسة في طريقة التئة تنفيذها .. جدول رقم (1) يوضح نماذج البحث

\begin{tabular}{|c|c|c|c|c|}
\hline الموقع & سنة التأسيس & المحتوى & النماذج & \\
\hline الكر ادة ـ الثـار ع الرئيسي & 1960 & وسطي & مقهى رضا علوان & 1 \\
\hline منطقة الجعيفر ـالثـار ع الرئيسي & 1995 & وسطي & مقهى البيروتي & 2 \\
\hline
\end{tabular}

(4-3) أداة البحث: لتحقيق أهداف البحث تم بناء استمارة ملاحظة ومن ثم استمارة تحليل اعتمدت فيها

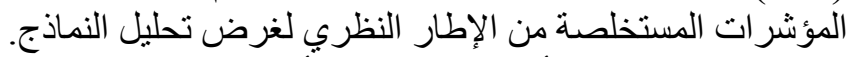

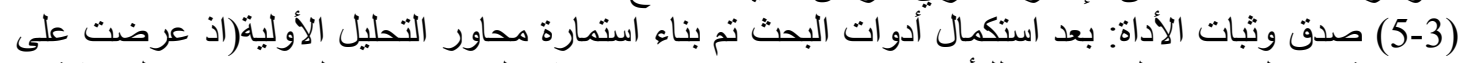

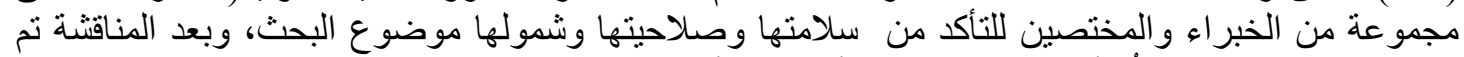

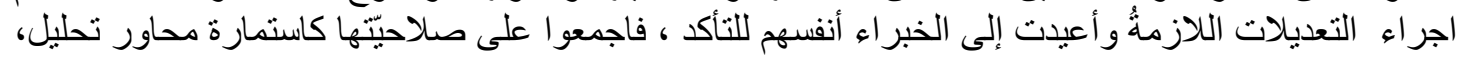

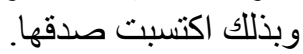

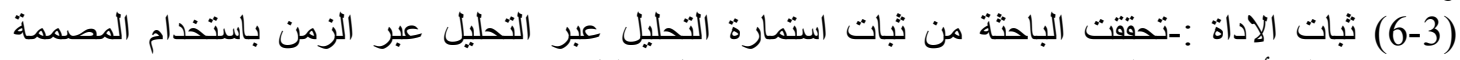

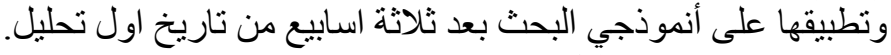

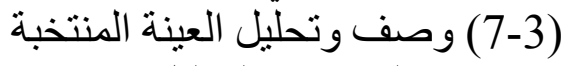

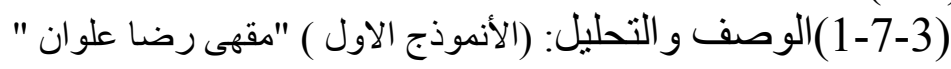




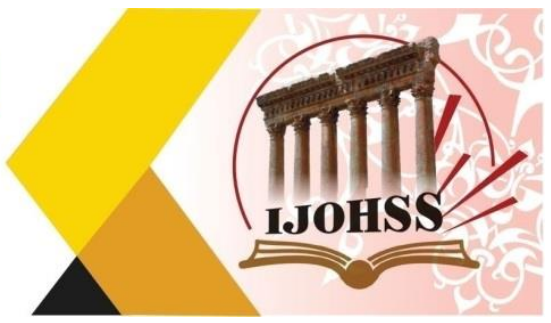

الوصف العام: يقع الأنموذج في منطقة الكرادة /العرصات على شارع رئيسي، ركني المحتوى ، مستطيل

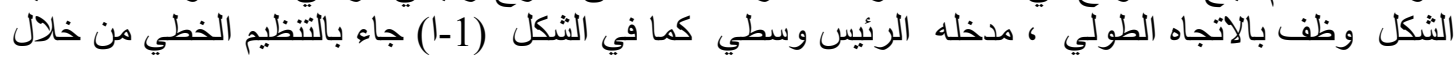

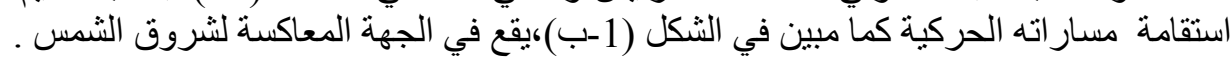

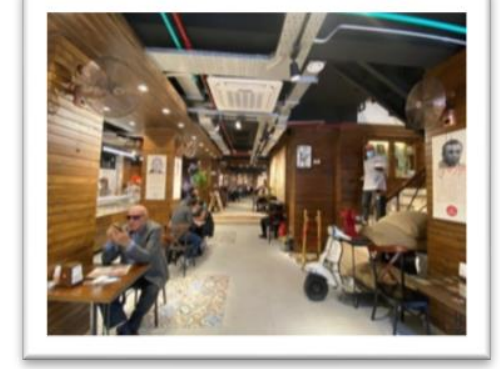

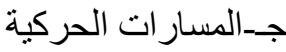

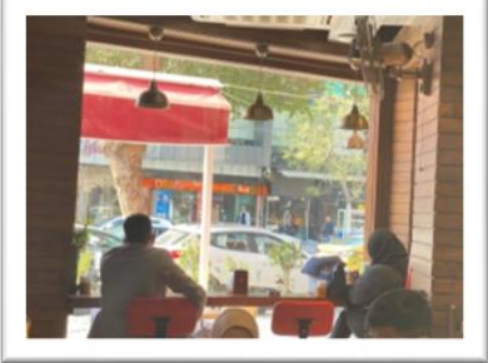

ب-يوضح اطلالة المقهى شكل (1) يوضح الانتماء في واقع حال الانموذج الاول

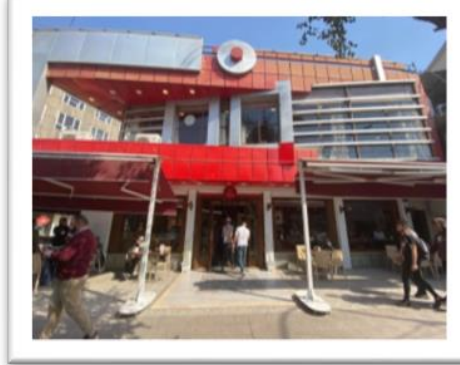

أ-يوضح و اجهة المقهى

الانتماء في التصميم الداخلي.

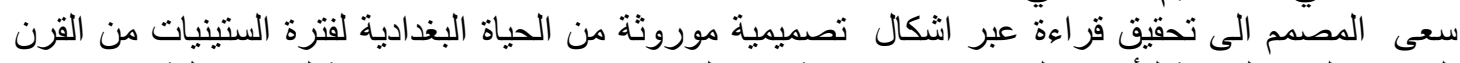

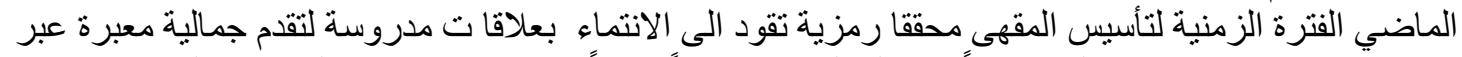

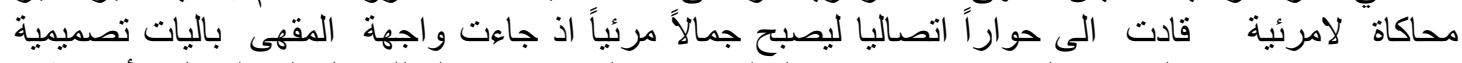

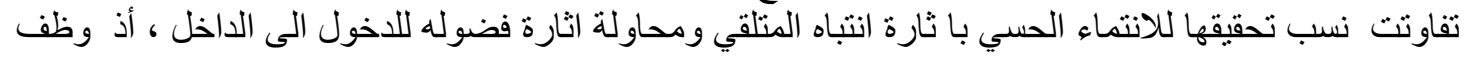

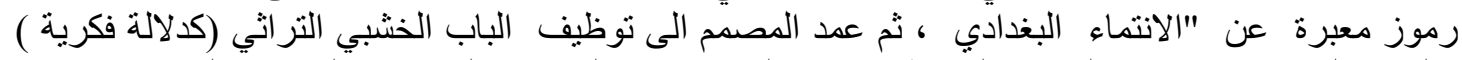

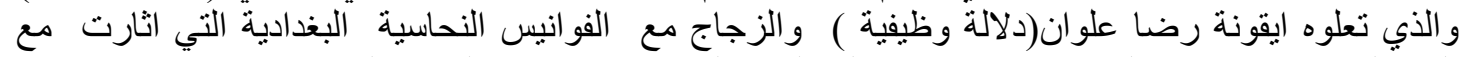

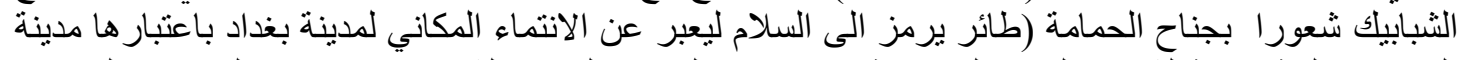

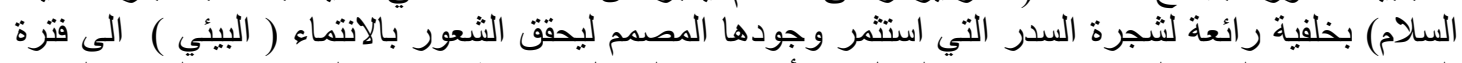

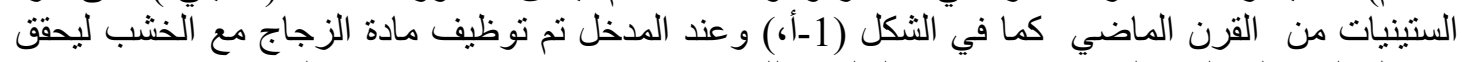

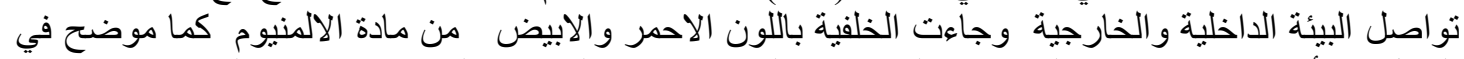

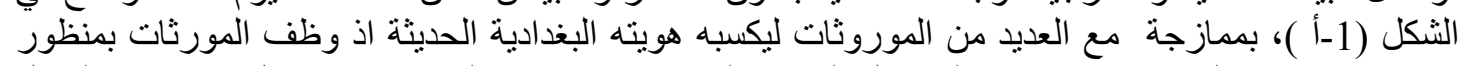

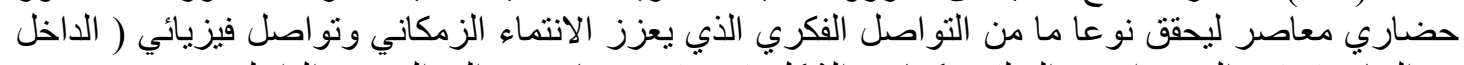

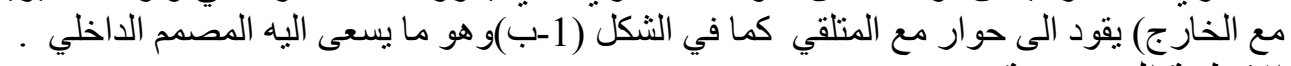
الانظمة التصميمية :-

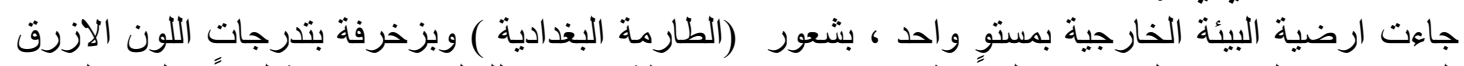

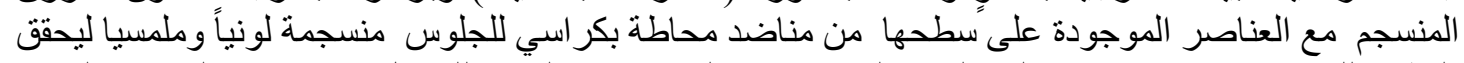

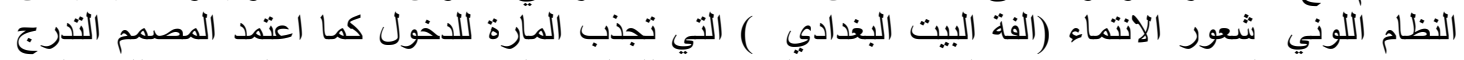

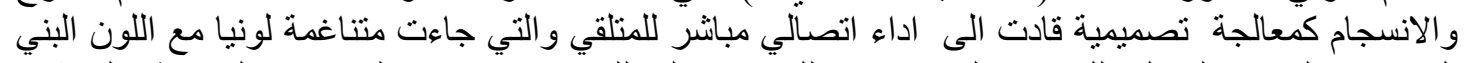

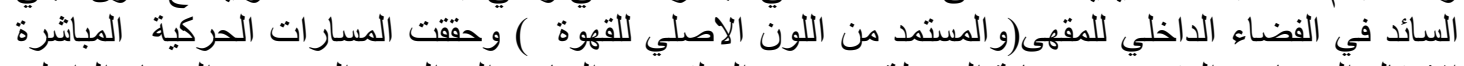

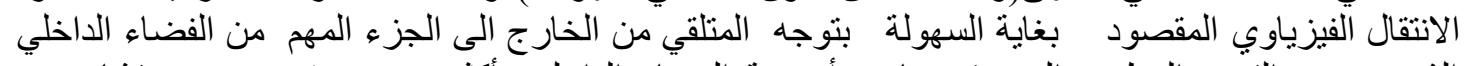

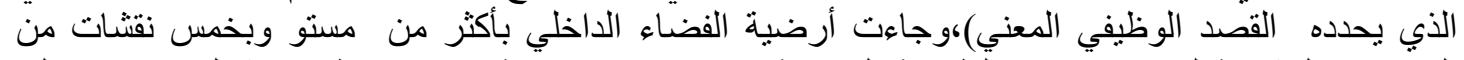

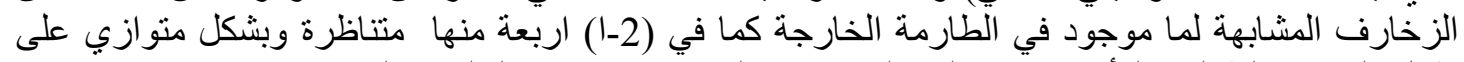

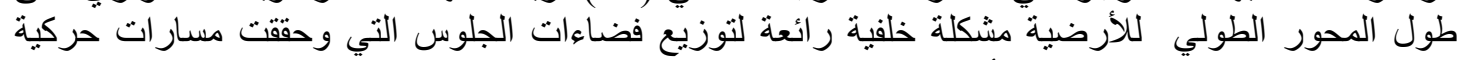

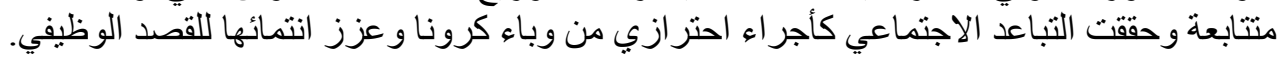


المجلة اللحولية اللملوم الآسانية والإمتصاعية International Journal on Humanities and Social Sciences website:www.ijohss.com Email:editor@ijohss.com ISSN: $2415-4822$

العدد(22) يوليو 2021 Volume (22) July 2021
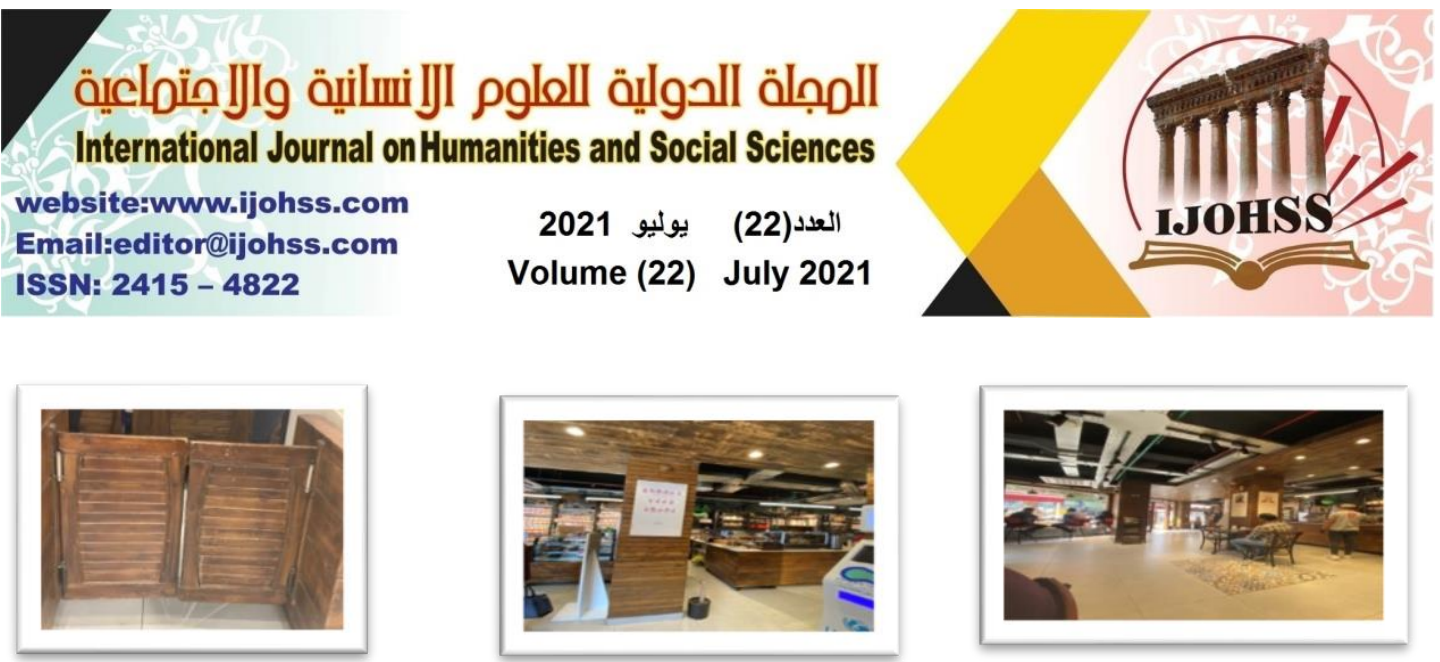

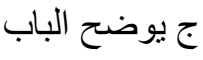

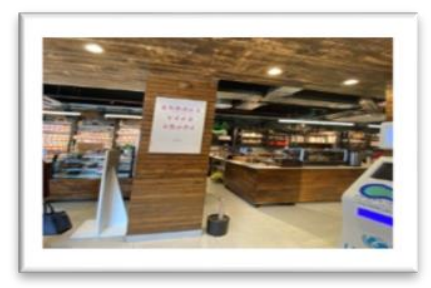

ب بوضح فضاء الطلبات

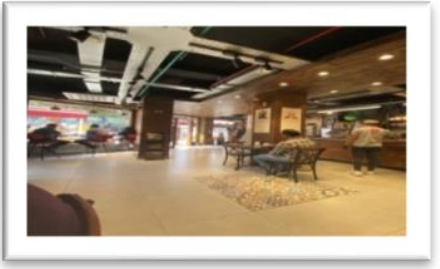

اليوضح الجدار الايسر المتزحلقة

شكل (2 ) يوضح واقع حال الانموذج الاول(تصوير الباحثة )

-جاء السقف متناغما مع بقية العناصر التصميمية ، كما في الثكل (2-أ)محقاً انتمائه الحسي و الفكري ، فضلاًا

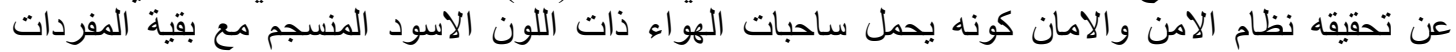

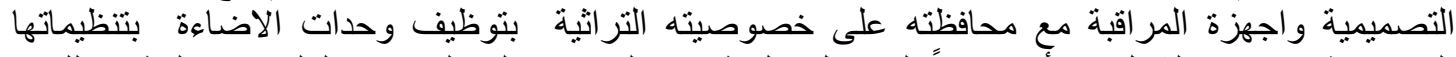

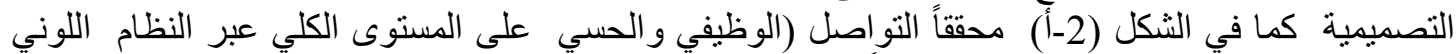

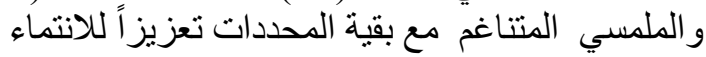

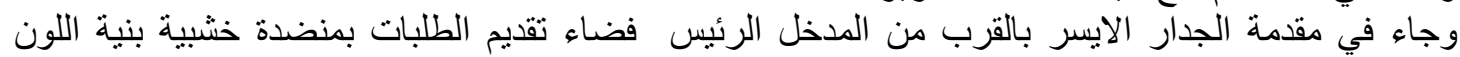

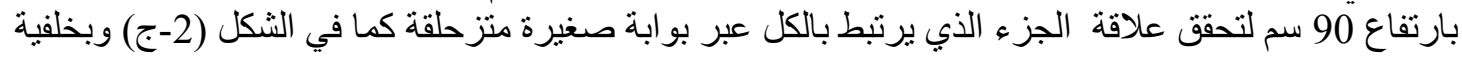

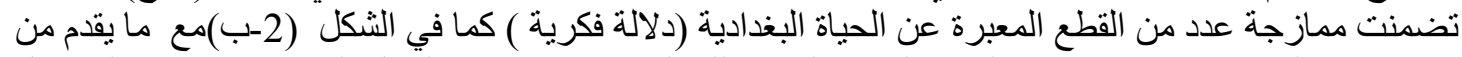

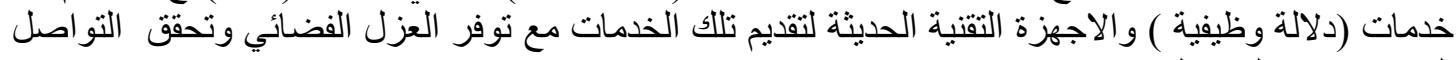
البصري عبر الباب الزجاجي
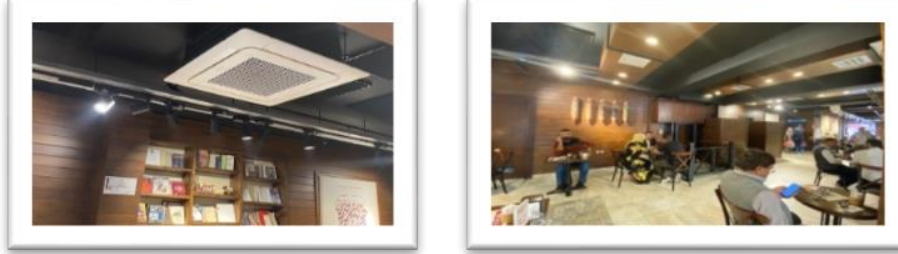

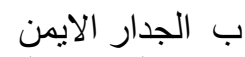

ج جوضح الجدار المقابل

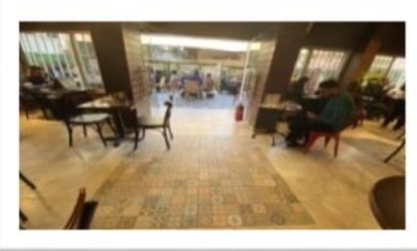

ا يوضح الطارمة الجانبية

شكل (3) يوضح الانتماء في البيئة الداخلية للمقهى(تصوير الباحثة )

الطارمة الجانبية والتي تحاكي مع النباتات الموظفة فيها الطارمة البغدادية التي تعزز شعور الالفة (البيت ) كما

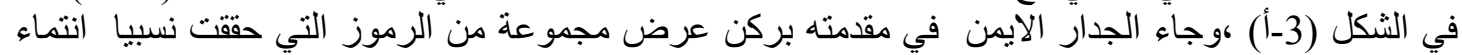

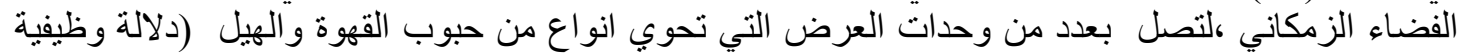

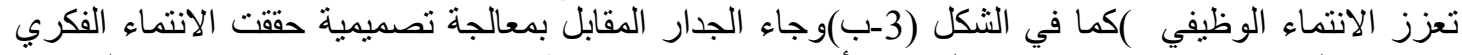

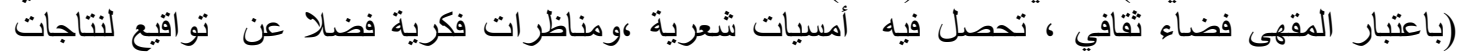

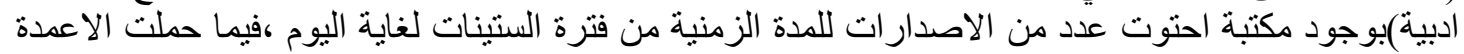

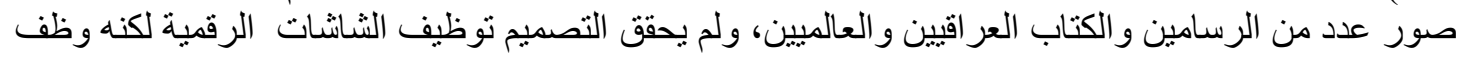

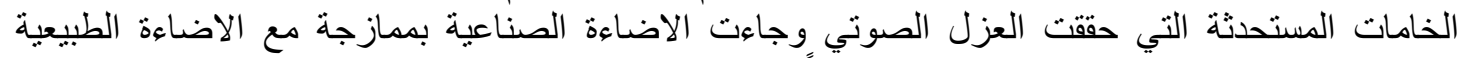

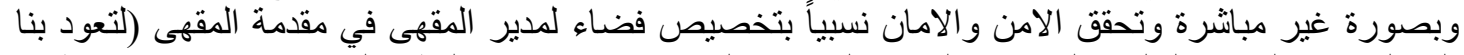

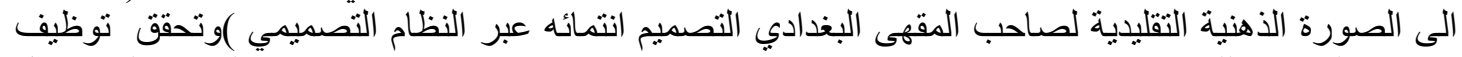

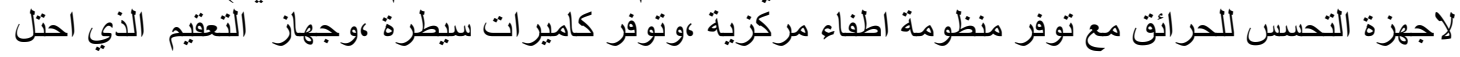




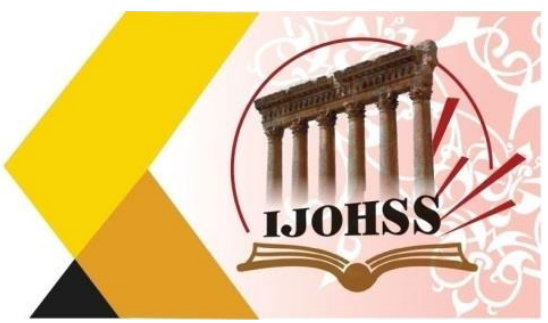

موقع متقدم من الفضاء الداخلي ، وحققت نسبياء قطع التأثيث فيه انتمائها (البيئي ، و الوظيفي ) كما في الكل (3ب)، حتى قائمة الطلبات جاءت على شكل الصحيفة اليومية البغدادية ، المطبو عة بالية نوحي بفترة الستينات من فن

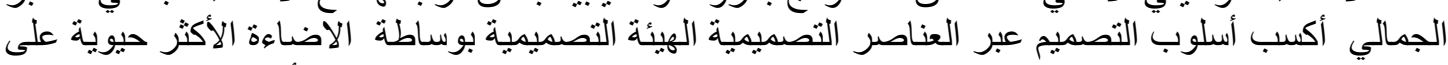

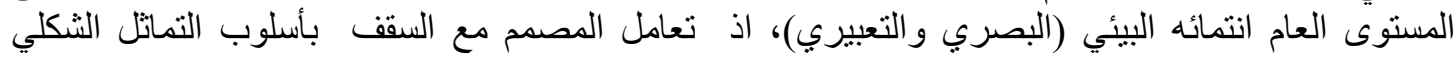

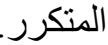

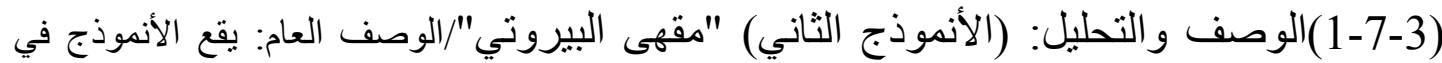

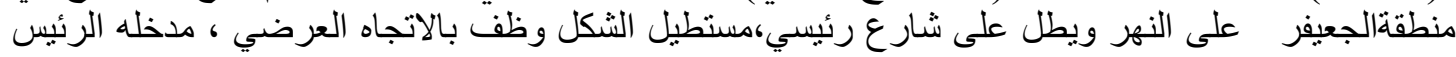

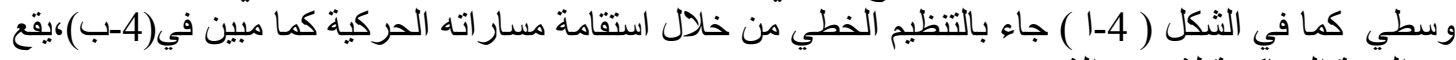
في الجهة المعاكسة لثروق الثمس (الثم
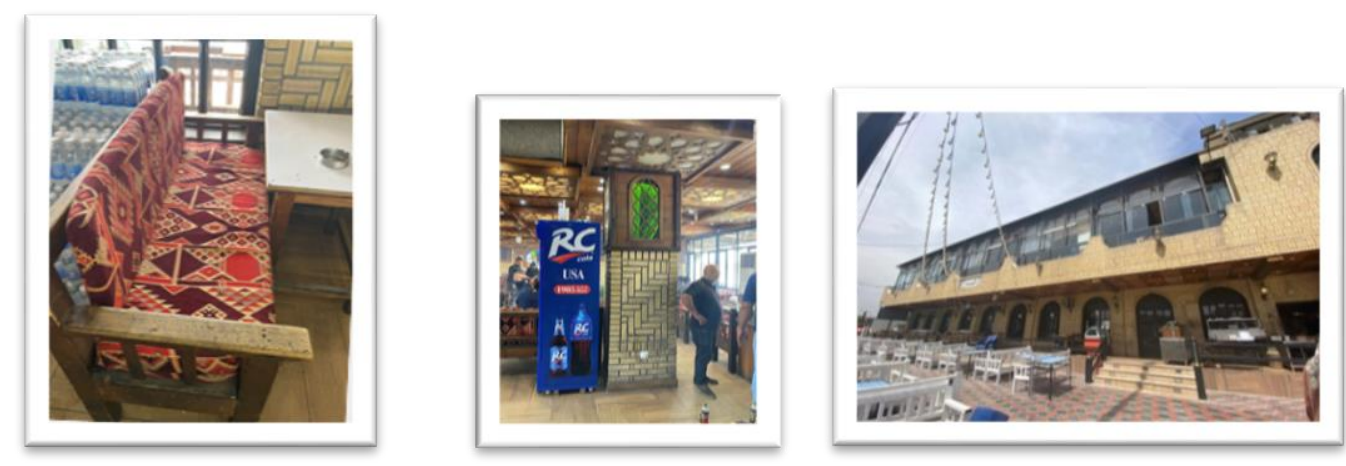

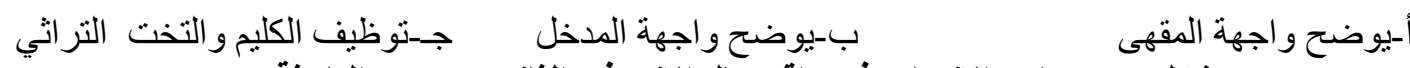

$$
\begin{aligned}
& \text { شكل (4) يوضح الانتماء في واقع حال الانموذج الثاني (تصوير الباحثة ) }
\end{aligned}
$$

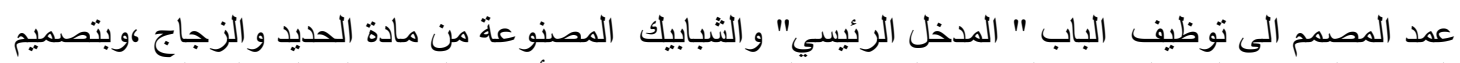

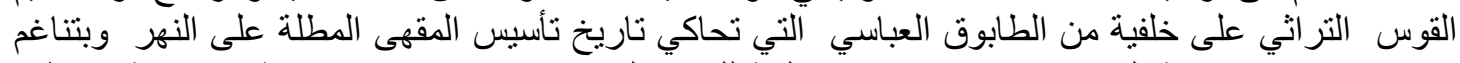

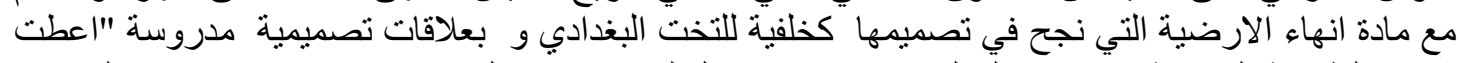

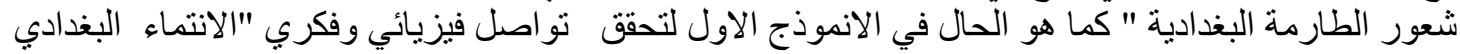

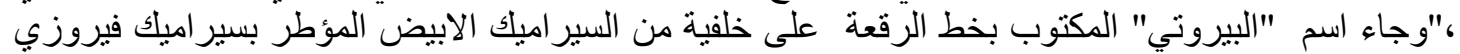

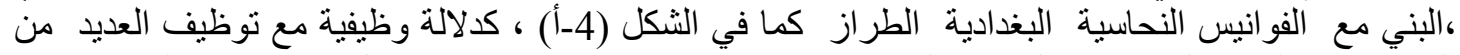

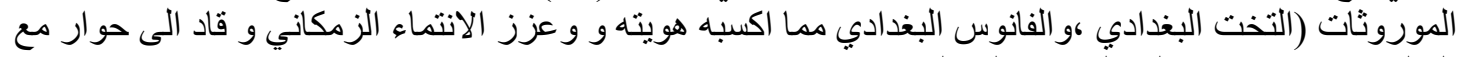

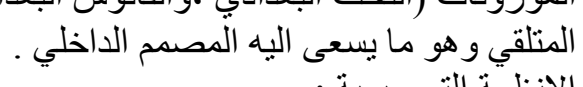

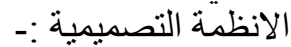

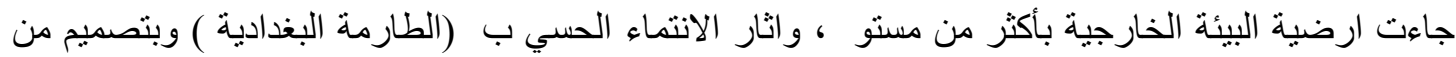

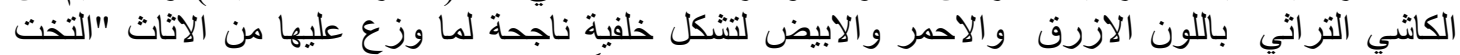

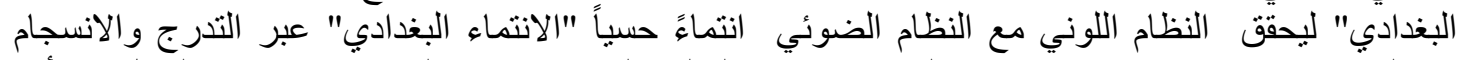

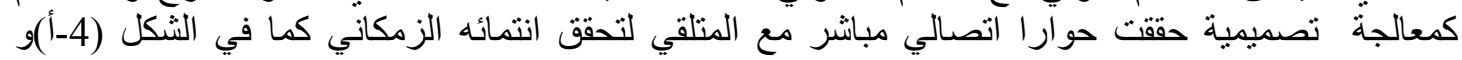

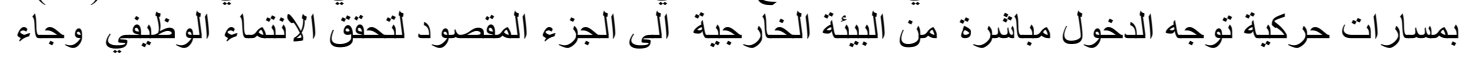

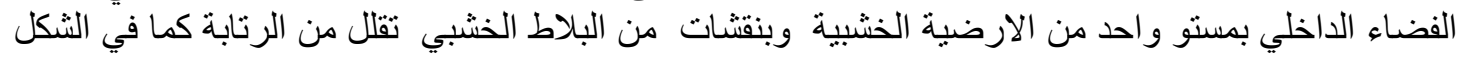

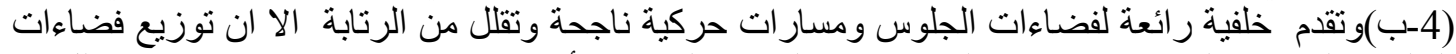

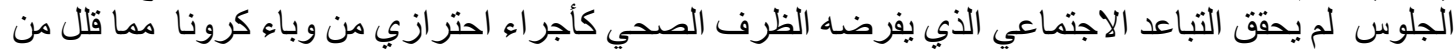

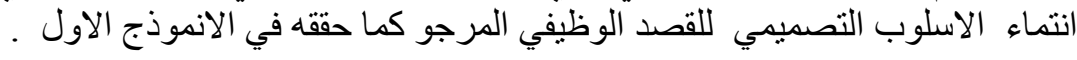


المجلة اللحولية اللملوم الآسانية والإمتصاعية International Journal on Humanities and Social Sciences website:www.ijohss.com Email:editor@ijohss.com

العدد(22) يوليو 2021 ISSN: $2415-4822$

Volume (22) July 2021

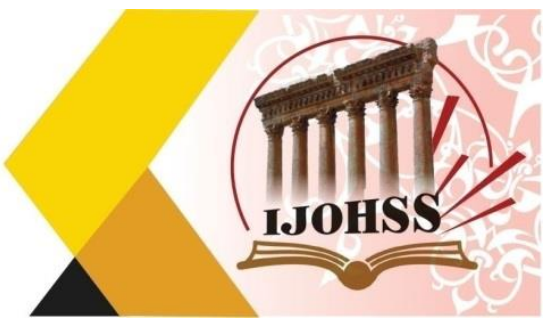

-جاء السقف بزخارفه المستمدة من الموروث العربي الاسلامي و البغدادي كما في الثكل(4-ب) و التي تحاكي التئي

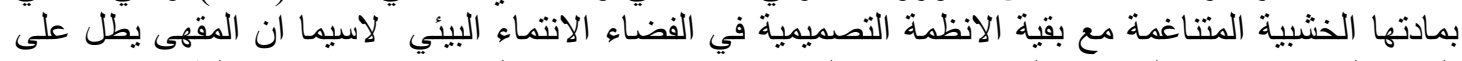

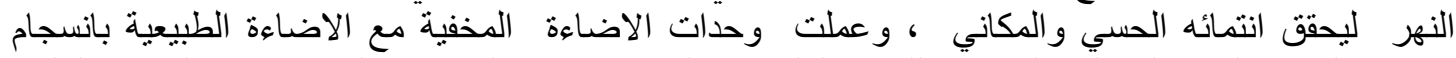

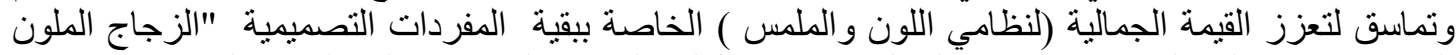

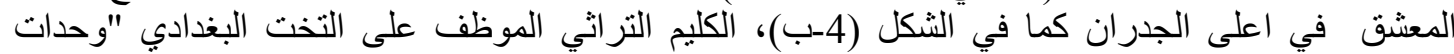

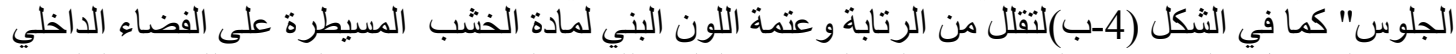

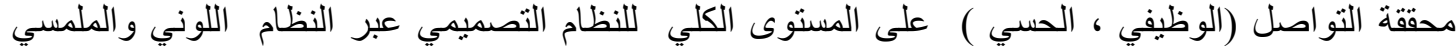

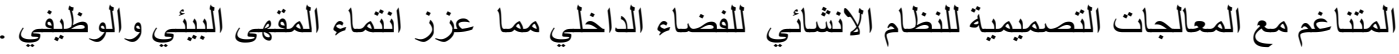

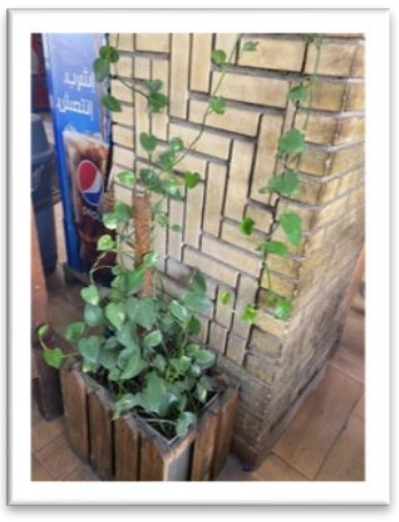

د. يوضح الارضية
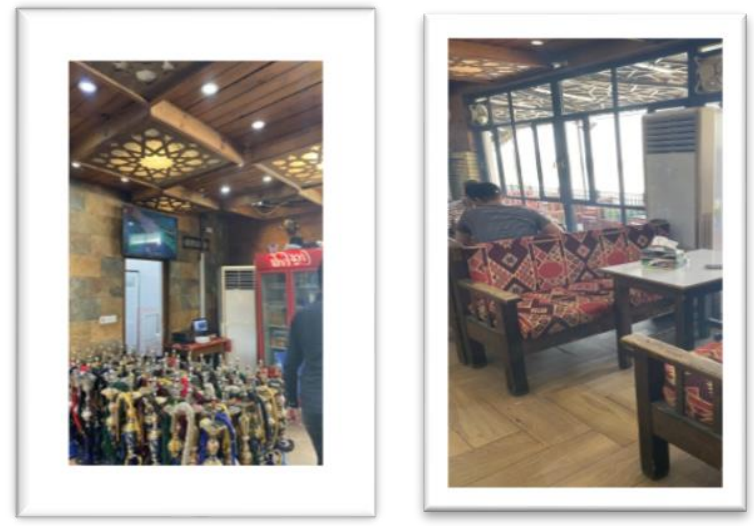

ج يوضح فضاء الطلبات

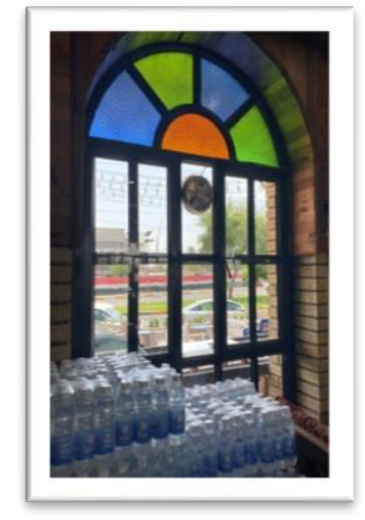

ا. يوضح الجدار الايسر ب. يوضح الجدار الايمن

شكل (5) يوضح الانتماء في البيئة الداخلية للأنموذج الثاني (تصوير الباحثة )

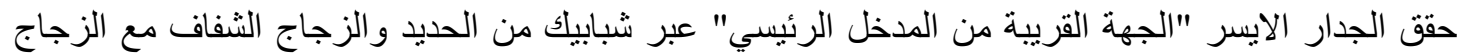

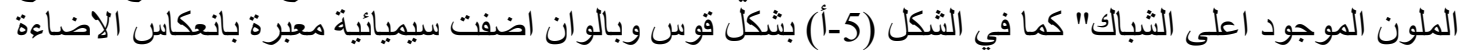

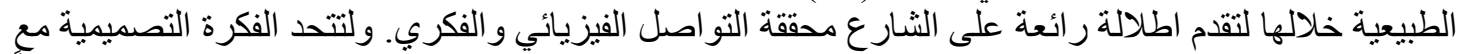

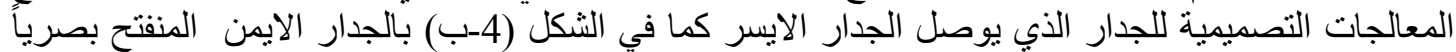

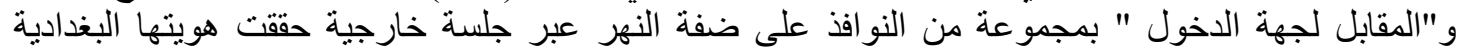

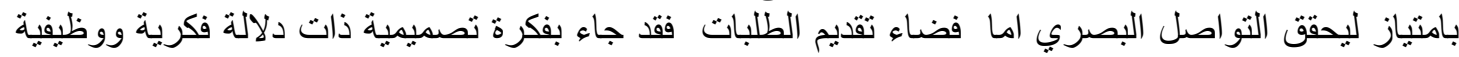

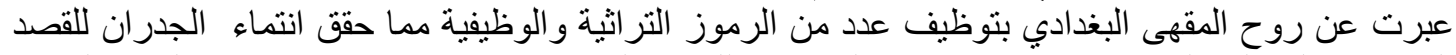

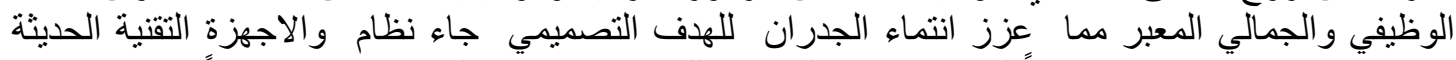

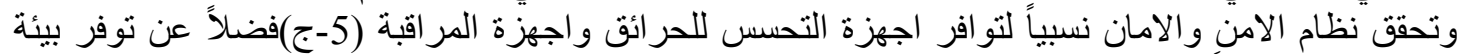

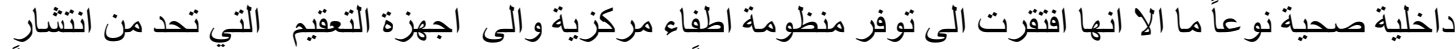

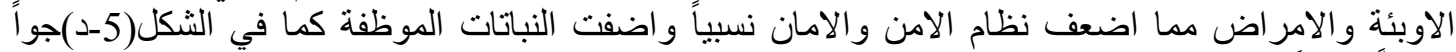

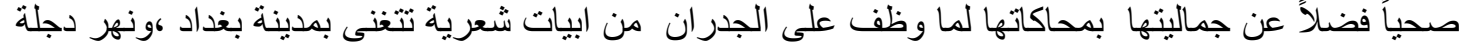

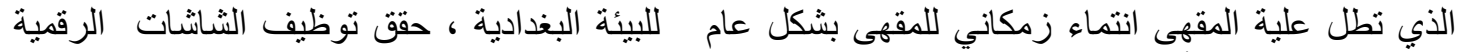

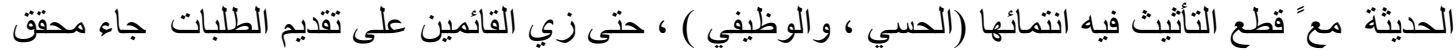

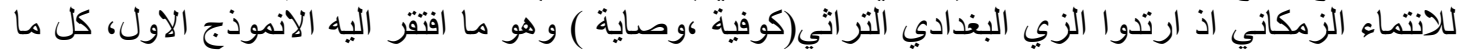

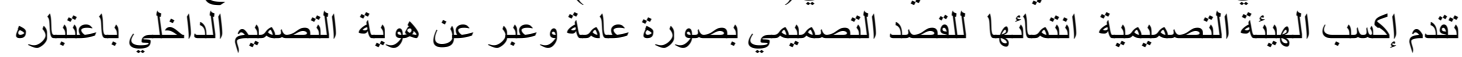

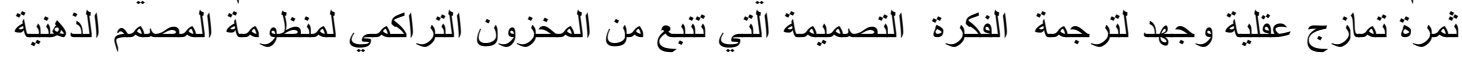
و التي عززت تمزت انتماء التصميم الداخلي للمقهى البغدادي. 


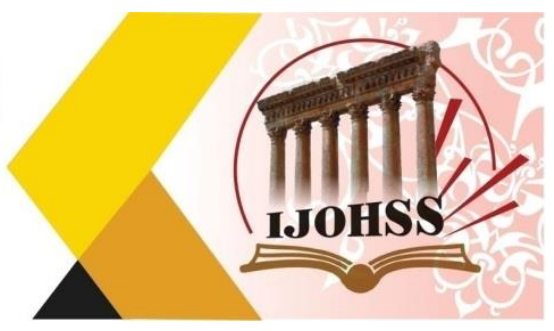

تحقيقا للهدف الاول للبحث توصل الباحث عبر تحليله للنماذج المنقاة إلى عددٍ من النتائج، كانت على الوجه

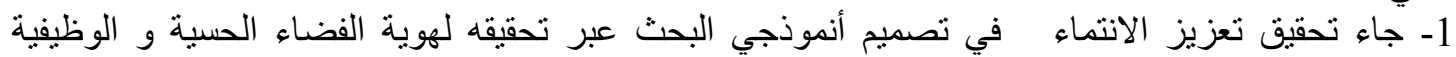

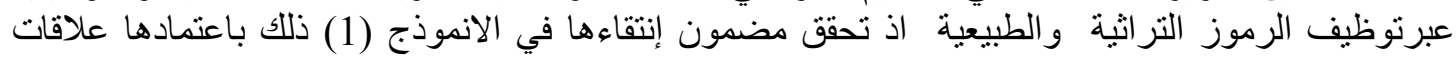

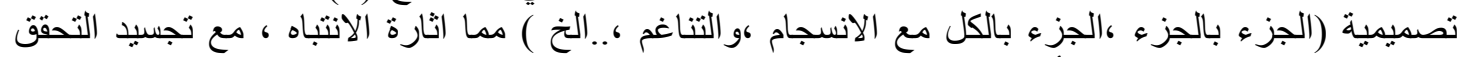

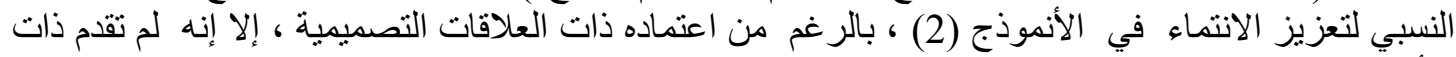

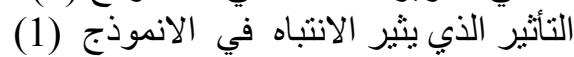

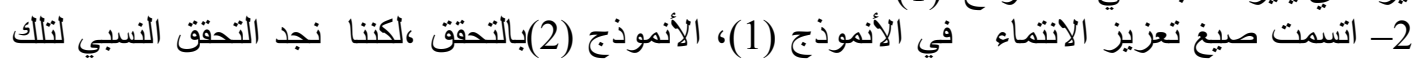

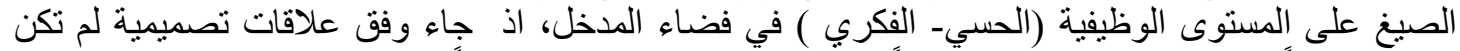

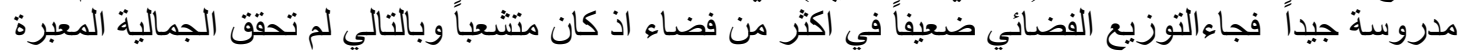

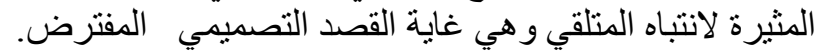

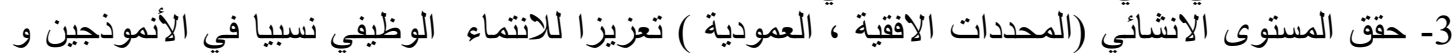

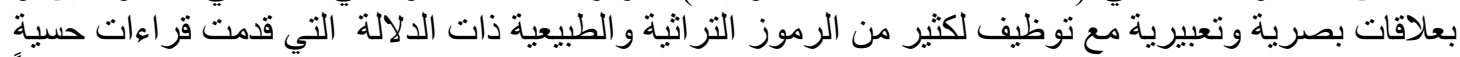

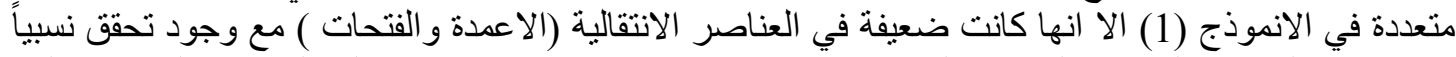

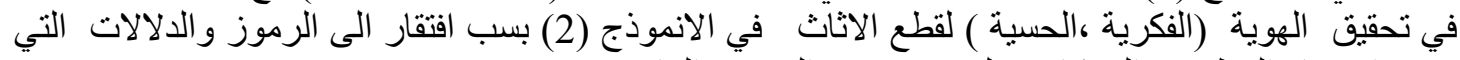

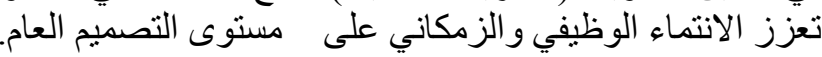

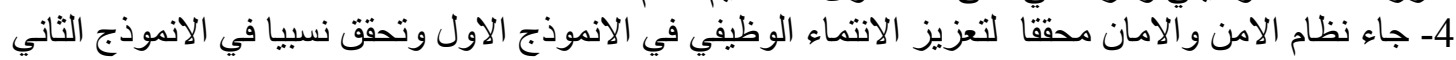
مع تفاوت دور ها في تحقيق القصد الونان مانقيفي.

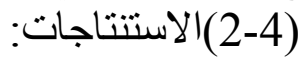

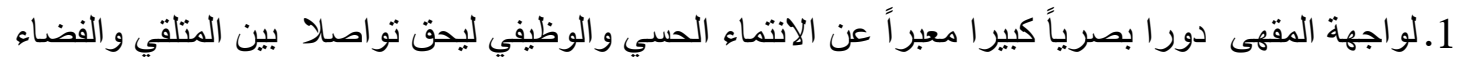

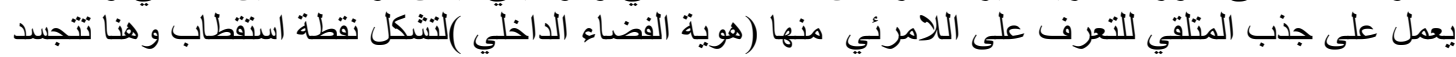
دور ها الدلالي المعزز لتلانتماء عبر الدلالة المعبرة عن هوية الفضاء الداخلية الفئي الوظيفية.

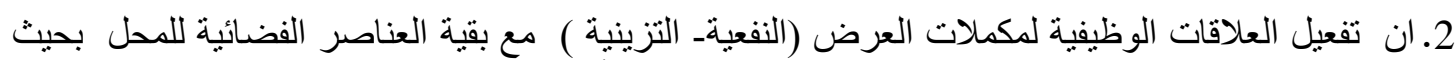

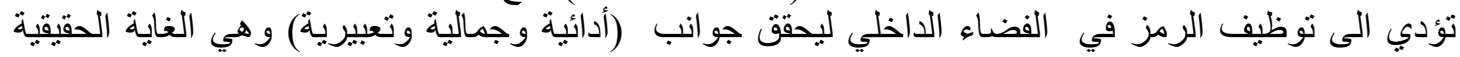

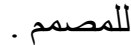

3. ان لتعزيز الانتماء الوظيفي ،الحسي أهية فاعلة فله اهمية في ادائية اجز اء الفضاء الداخلي للمقهى (الوظيفية

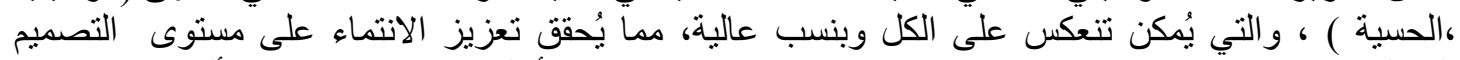

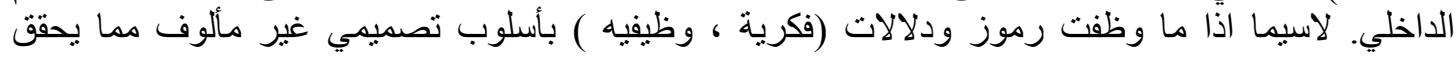

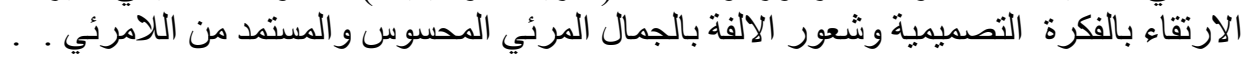

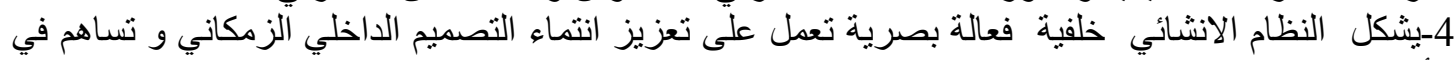

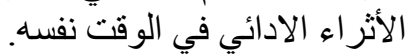

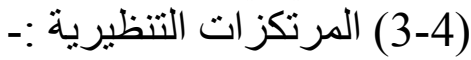

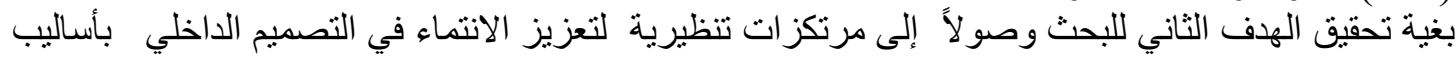

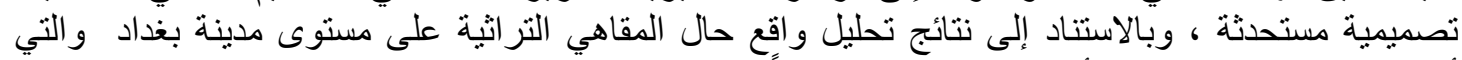

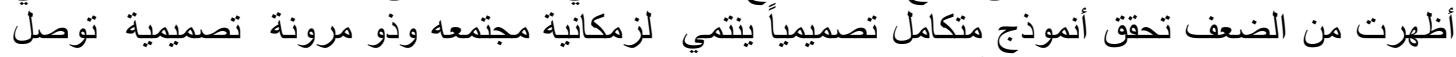
البحث إلى المرتكزات التصميمية الآتية:1-من الضرورة ان يكون المقهى التراثي قريباً من عوامل الجذب الثقافي و المر اكز السياحية ويبتعد عن مراكز

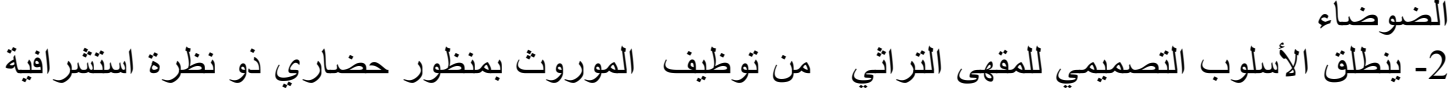
مستقبلية بأعتبار مركز للأبداع ومعلم سياحي ذلو رسالة ثقافية وحضارية للسياح و غير هم . 


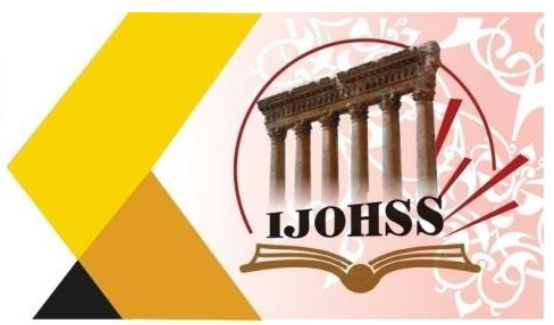

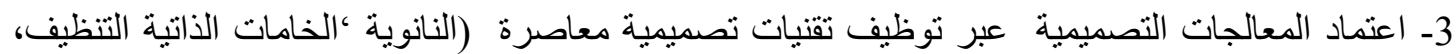

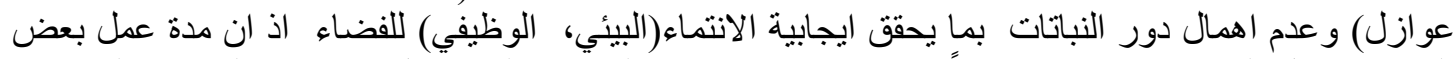

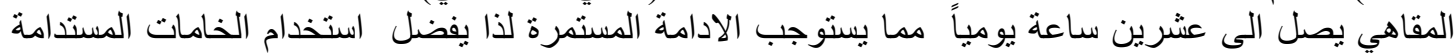

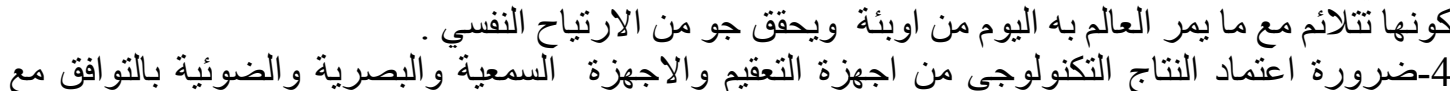
توظيف الدلالات والترميز لتحقيق الانتماء الوظيفي لوني (تعريفي ) .

لأنة الخبراء 1 - أ.د. فاتن عباس لفته/كلية الفنون الجميلة /جامعة بغداد.

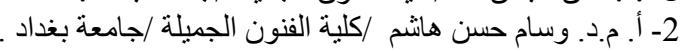

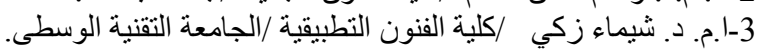

1- الامام، علاء الدين كاظم ،2013خطاب التصديم الداظلي و وانعكاسه السلوكي في فضاء/ت السلطة ،

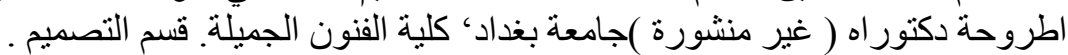

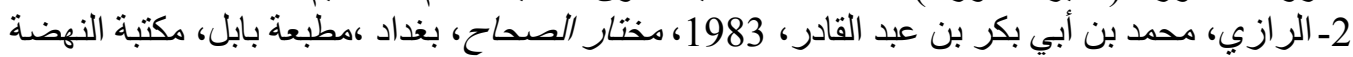

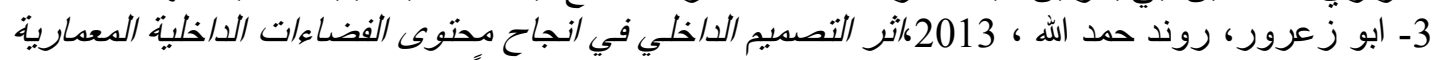

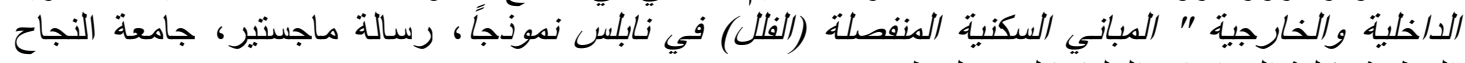

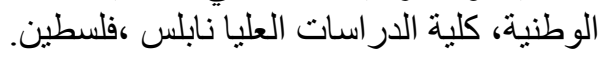

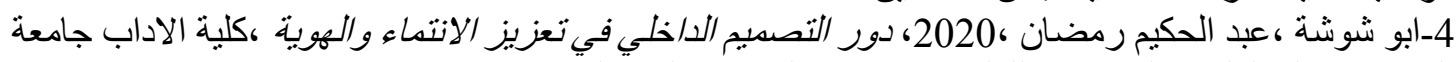

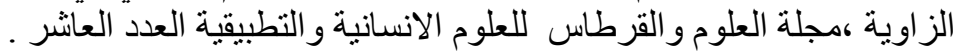

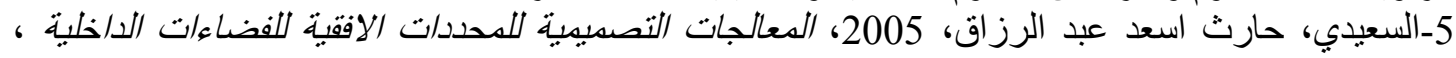

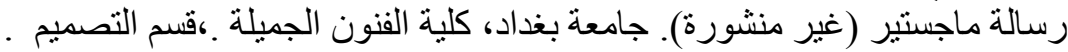

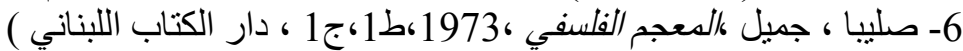

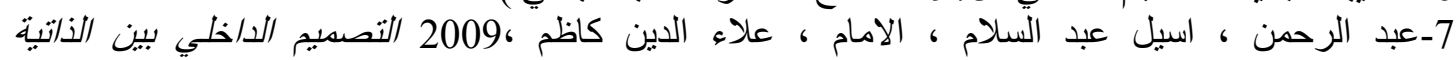

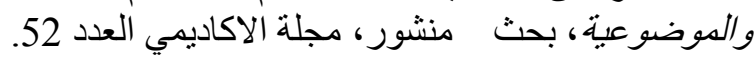

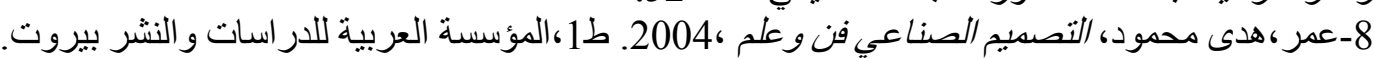

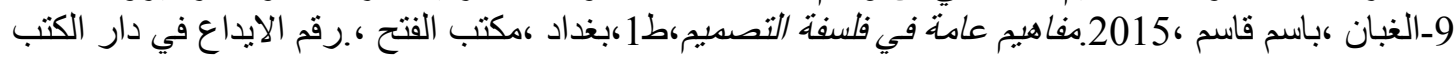

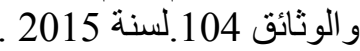

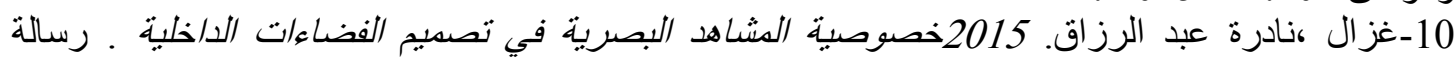
ماجستير (غير منشورة). جامعة بغداد ـكلية الفنون الجميلة ، قسم التصميح.

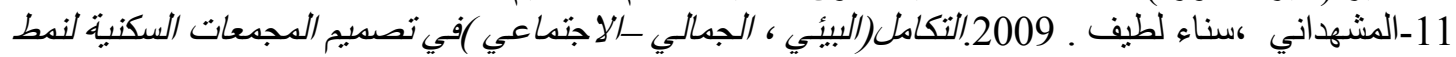
متعدد الاسر (تقويم التجربة العراقبة )رسالة ماجستير (غير منشوره) ، كلية التهنسة ،السم المعماري ، جامعة

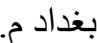

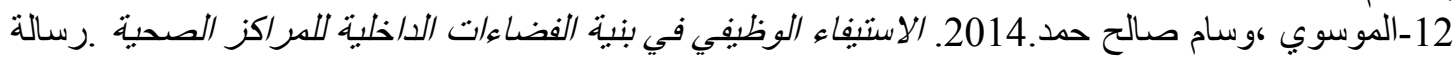

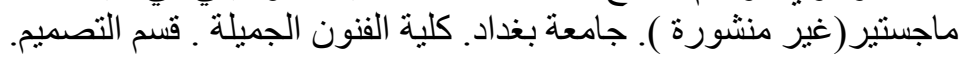

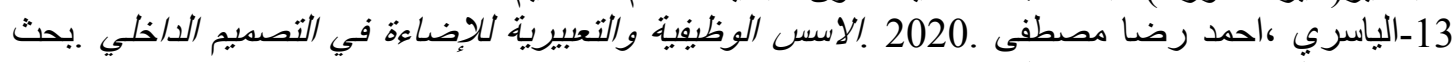

\section{References}

منشور .مجلّة دراسات تربوية .العدد 49.

1. Al-Imam, Alaa Alden Khadim, 2013. The Speech of the Internal Design and Its Behavioral Reflection in Power Buildings.(Unpublished Doctoral's Dissertation) Baghdad University, College of Fine Arts, Design Department. 


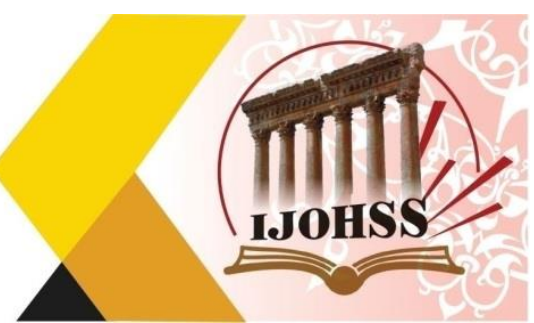

2. Al-Razi, M., (1983). Muktar Al-Sahah . Baghdad: Babylon Printing, Al-Nadaa Library.

3-Abo Zaror, Rond Hamd Allah. 2013. The Effect of Interior Design in the Success of the Content of the Interior Architectural Building Internal and External "The Separate Buildings (Villas) in Nablus as a Model. A Master's Thesis. Al-Najah National University. College of HigherStudiesNablusPalestine. 4- Abo Shosha , Abdul Al-Hakim Ramadan. 2020. The Role of Interior Design in Strengthening the Feeling of Belonging and Identity. College of Arts Al-Zawia University, Journal of Science and Paper for Humanities and Applied Sciences, Issue 10 .

5. Al-Saidy, Harth Assad Abdelrazaq. 2005. The Designing Treatments of the Horizontal Delimiters for Interior Buildings. (Unpublished Master's Thesis). Baghdad University. College of Fine Arts. Design Department.

6-Saliba, J. (1973), Philosophical Lexicon, $1^{\text {st }}$ P. ( $1^{\text {st }}$ ed.) Beirut: The Lebanese Book House.

7. Abdel Rahman, Aseel Abdel. Salam, Al-Imam, Alaa Alden Khadim. 2009. Interior Design between Subjectivity and Objectivity. A Published Paper. Al-Academy Magazine Issue 52.

8- Omar, Hudaa Mahmoud, Artificial Design as an Art and Science. The Arabian Institution for Studies and Publishing. Beirut. 9-. Al-Gaban, Basam Qasim. 2015. General Concepts in the Philosophy of Design. $1^{\text {st }}$ ed. .Baghdad. Al-Fatah Office. Deposit number in the House of Books and Documents 104 for the year 2015.

10.Gazal, Nadira Abdelrazaq. 2015. The Privacy of Visual Scenes in Designing Interior Buildings. (Unpublished Master's Thesis). Baghdad University. College of Fine Arts. Design Department.

11. Al-Mashhadani, Sana Latif. 2009. The (Environmental, Aesthetic and Social) Integration in Designing Residential Complex Design for Multi-family Style (Evaluating The Iraqi Experience). Unpublished Master's Thesis, College of Engineering, Architecture Department. BaghdadUniversity.

12. Al-Mosawy, Wasam Salah Hamad. 2014. Functional Fulfilment in the Interior Buildings of the Health Centers.Unpublished Master's Thesis). Baghdad University. College of Fine Arts. Design Department.

13. Al-Yasary, Ahmed Ridah Mustafaa. 2020. The Functional and Expressive Foundations of Lighting in Interior Design. A Published Paper. Magazine of Educational Studies. Issue 49. 